\title{
Exchange of single amino acids at different positions of a recombinant protein affects metabolic burden in Escherichia coli
}

\author{
Natalie Rahmen ${ }^{1}$, Alexander Fulton ${ }^{2}$, Nina Ihling ${ }^{1}$, Marzio Magni ${ }^{1}$, Karl-Erich Jaeger ${ }^{2,3}$ and Jochen Büchs ${ }^{1 *}$
}

\begin{abstract}
Background: Escherichia coli is commonly used in academia and industry for expressing recombinant proteins because of its well-characterized molecular genetics and the availability of numerous expression vectors and strains. One important issue during recombinant protein production is the so-called 'metabolic burden': the material and energy normally reserved for microbial metabolism which is sapped from the bacterium to produce the recombinant protein. This material and energy drain harms biomass formation and modifies respiration. To the best of our knowledge, no research has investigated so far whether a single amino acid exchange in a recombinant protein affects the metabolic burden phenomenon. Thus, in this study, 15 E. coli BL21(DE3) clones expressing either the fusion tags, a recombinant wild type lipase, or 13 different lipase variants are investigated to quantitatively analyze the respective effects of single amino acid exchanges at different positions on respiration, biomass and protein production of each clone. Therefore, two small-scale online monitoring systems, namely a Respiration Activity MOnitoring System (RAMOS) and a microtiter plate based cultivation system (BioLector) are applied.

Results: Upon expression of all enzyme variants, strong variations were found in the Oxygen Transfer Rate (OTR), biomass and protein (lipase) production of the respective E. coli clones. Two distinct patterns of respiration behavior were observed and, so, the clones could be classified into two groups (Type A and B). Potential factors to explain these patterns were evaluated (e.g. plasmid copy number, inclusion body formation). However, no decisive factor could yet be identified. Five distinct cultivation phases could be determined from OTR curves which give real-time information about carbon source consumption, biomass and protein production. In general, it was found that the quantity of product increased with the duration of active respiration.

Conclusions: This work demonstrates that single amino acid exchanges in a recombinant protein influence the metabolic burden during protein production. The small-scale online monitoring devices RAMOS and BioLector enable the real-time detection of even smallest differences in respiration behavior, biomass and protein production in the $E$. coli clones investigated. Hence, this study underscores the importance of parallel online monitoring systems to unveil the relevance of single amino acid exchanges for the recombinant protein production.
\end{abstract}

Keywords: Recombinant protein, Metabolic burden, Escherichia coli, Bacillus subtilis lipase A (BSLA), Amino acid exchange, Metabolic activity, Online monitoring, Oxygen Transfer Rate (OTR), Respiration Activity MOnitoring System (RAMOS), BioLector

\footnotetext{
* Correspondence: jochen.buechs@avt.rwth-aachen.de

${ }^{1} \mathrm{AVT}$ - Biochemical Engineering, RWTH Aachen University, Worringerweg 1,

D-52074 Aachen, Germany

Full list of author information is available at the end of the article
}

() Biomed Central (c) 2015 Rahmen et al.; licensee BioMed Central. This is an Open Access article distributed under the terms of the Creative Commons Attribution License (http://creativecommons.org/licenses/by/4.0), which permits unrestricted use, distribution, and reproduction in any medium, provided the original work is properly credited. The Creative Commons Public Domain Dedication waiver (http://creativecommons.org/publicdomain/zero/1.0/) applies to the data made available in this article, unless otherwise stated. 


\section{Background}

Among many available microbial systems, Escherichia coli is the most commonly used prokaryotic expression system for the production of recombinant proteins. This is due to its well-known genetics, its ability to grow rapidly to high cell densities on inexpensive mineral media, as well as the large number of available cloning vectors and optimized host strains [1,2].

A frequently used E. coli-based expression system is the bacteriophage T7 RNA polymerase-controlled system [3] under control of the lac operon. Induction with isopropyl $\beta$-D-thiogalactopyranoside (IPTG) requires the manual addition of the inducer as well as biomass monitoring to determine the optimal induction time point. By contrast, autoinduction is controlled by the metabolism of the expression host, i.e. E. coli, and thus is distinguished by cell growth and subsequent product formation [4-6]. To achieve this, a carbon source mixture of glucose, glycerol, and lactose is commonly used. During the initial growth phase, glucose is preferentially consumed and protein formation is suppressed by catabolite repression [7]. Once glucose is depleted, lactose and glycerol are taken up and consumed. Lactose is partially converted into allolactose, which acts as the physiological inducer of the lac operon [5]. Glycerol serves as additional energy source. Several modified complex autoinduction media are based on the composition described by Studier [4]. Commercial sources of such media are also available, but are often expensive and have an undefined composition [6]. Mineral autoinduction media have a defined chemical composition which allows a better understanding of metabolic processes during induction and protein expression.

The production of recombinant proteins is one of the most energy and raw material consuming processes. It activates stress responses and causes significant alterations in host cell metabolism. 'Metabolic burden' is defined as the draining of raw materials and energy from the physiological microbial metabolism as the result of this protein production [8-11]. Many reviews have summarized the main challenges in recombinant protein production and potential factors influencing the metabolic burden, as well as strategies to overcome metabolic burden and optimize protein production [12-17]. One of the most prevalently observed changes in host-cell physiology due to metabolic burden is a decrease in growth rate which can be impaired in different ways $[18,19]$. The general influence of the amino acid sequence of recombinant proteins on the metabolic burden phenomenon has already been evaluated in some studies [20,21]. Palmen et al. found that slight differences in the amino acid composition of a cofactordependent enzyme significantly affect the expression and cultivation progress. They correlated the binding strength of the cofactor thiamin diphosphate of the recombinant benzoylformate decarboxylase to the differences in the metabolic activity [20]. Furthermore, the metabolic costs of the amino acid biosynthesis in $E$. coli were calculated as high-energy phosphate bonds contained in ATP and GTP molecules, and according to available hydrogen atoms in NADH, NADPH, and $\mathrm{FADH}_{2}$ molecules, respectively [22,23]. Tryptophan $(\mathrm{W})$, phenylalanine $(\mathrm{F})$, tyrosine $(\mathrm{Y})$, histidine $(\mathrm{H})$ and methionine $(\mathrm{M})$ were identified as amino acids leading to the highest energetic costs during their biosynthesis [22]. For the cellular stress caused by the recombinant protein production, Bonomo and Gill also discovered that the amino acid sequence itself plays an important role [21]. Using the same host organism and expression system, they investigated the growth behavior upon expression of two different polypeptides. The first polypeptide was composed of the most rarely used amino acids causing the highest energetic costs, whereas the second one was composed of the most abundant and, thus, energetically inexpensive amino acids. The expression of the first polypeptide led to a strong decrease in growth [21] due to a stringent-like response [24-26].

Some approaches to determine and quantify the metabolic burden [27-31] are either based on sampling and subsequent offline monitoring techniques or described for large-scale fermentations requiring considerable equipment, chemicals, and time.

This study aims to investigate the influence of single amino acid exchanges at different positions of a recombinant enzyme on metabolic activity and expression of the host $E$. coli BL21(DE3) using two small-scale online monitoring devices. The first device is the Respiration Activity MOnitoring System (RAMOS) [32,33] which enables the online measurement of the Oxygen Transfer Rate (OTR) as characteristic parameter for the metabolic activity of the bacteria. The second device is the BioLector $[34,35]$ which measures scattered light and fluorescence to trace biomass and protein formation during cultivation. Within this study, 15 E. coli BL21(DE3) clones that only differ by the exchange of single amino acids are investigated. Thereby, the amino acid exchanges are distributed over the entire amino acid sequence (Table 1). The target protein is the lipase LipA from Bacillus subtilis (BSLA) [36] which is fused to a flavin-based fluorescent protein (FbFP) derived from the Light, Oxygen, Voltage (LOV) domain of the Bacillus subtilis YtvA photoreceptor (LOV tag) $[37,38]$. For cultivation under inducing conditions a mineral autoinduction medium was used.

\section{Results and discussion}

Table 1 lists the investigated E. coli BL21(DE3) clones. Each clone is named after the particular enzyme variant 
Table 1 Applied clones and abbreviations

\begin{tabular}{|c|c|}
\hline Clone & Abbreviation \\
\hline E. coli BL21(DE3):pET22b(+)-His - -LOV & His-LOV \\
\hline E. coli BL21(DE3):pET22b(+)-His $\sigma_{-}$LOV-BSLA-wt & $\begin{array}{l}\text { Wild type enzyme } \\
\text { (His-LOV-BSLA) }\end{array}$ \\
\hline E. coli BL21(DE3):pET22b(+)-His 6 -LOV-BSLA-Ala1Trp & A1W \\
\hline E. coli BL21(DE3):pET22b(+)-His ${ }_{6}$ LOV-BSLA-His10Asp & $\mathrm{H} 10 \mathrm{D}$ \\
\hline E. coli BL21(DE3):pET22b(+)-His 6 -LOV-BSLA-Ile12Cys & $112 \mathrm{C}$ \\
\hline E. coli BL21(DE3):pET22b(+)-His ${ }_{6}$-LOV-BSLA-Phe17Pro & F17P \\
\hline E. coli BL21(DE3):pET22b(+)-His ${ }_{6}$-LOV-BSLA-Lys23stop & K23stop \\
\hline E. coli BL21(DE3):pET22b(+)-His $\sigma_{6}$-LOV-BSLA-Ser56Pro & S56P \\
\hline E. coli BL21(DE3):pET22b(+)-His 6 -LOV-BSLA-Asp91Arg & D91R \\
\hline 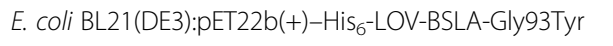 & G93Y \\
\hline E. coli BL21(DE3):pET22b(+)-His 6 -LOV-BSLA-Val99Lys & V99K \\
\hline $\begin{array}{l}\text { E. coli BL21(DE3):pET22b(+)-His } 6 \text {-LOV-BSLA- } \\
\text { Leu102Trp }\end{array}$ & L102W \\
\hline E. coli BL21(DE3):pET22b(+)-His 6 -LOV-BSLA-Ser167Pro & S167P \\
\hline $\begin{array}{l}\text { E. coli BL21(DE3):pET22b(+)-His } 6 \text {-LOV-BSLA- } \\
\text { Lys 170Glu }\end{array}$ & K170E \\
\hline $\begin{array}{l}\text { E. coli BL21(DE3):pET22b(+)-His }{ }_{6}-\text { LOV-BSLA- } \\
\text { Gly175Phe }\end{array}$ & G175F \\
\hline
\end{tabular}

The investigated E. coli BL21(DE3) clones contain plasmid pET22b(+) harboring the gene encoding fusion tags, wild type BSLA or BSLA variants. Each variant contains a single amino acid exchange at a different position chosen randomly and distributed over the entire enzyme sequence of 181 amino acids.

it expresses. One clone expresses a fusion of $\mathrm{N}$-terminal polyhistidine $\left(\mathrm{His}_{6}\right.$ ) tag and LOV tag $[37,38]$ (Additional file 1A). The other clones express wild type Bacillus subtilis lipase A (BSLA) or BSLA variants fused to $\mathrm{His}_{6}$ and LOV tag (Additional file 1B). Each BSLA variant contains a single amino acid exchange at a different position chosen randomly and distributed over the entire enzyme sequence of 181 amino acids. In variant K23stop the natural amino acid at position 23 (lysine) is replaced by a stop codon leading to a truncated protein.

An overview of the underlying cultivation procedure, the different applied cultivation systems and the determined online and offline data is given in Figure 1. A detailed description can be found in the Methods section.

\section{Precultivations under non-inducing conditions}

The precultivations under non-inducing conditions were consecutively performed in complex and mineral medium, respectively, to compare the respiration behavior and to determine the optimal OTR and time point for the inoculation of the subsequent culture (Figure 2). For the first precultivation, the investigated clones were cultivated in complex TB medium with glycerol as the main carbon source.

As illustrated in Figure 2A, the OTR curves of all clones depict a quite similar respiration behavior. They show the typical growth of $E$. coli in TB medium as described earlier [39] and as also observed in other studies where E. coli was cultivated under similar conditions $[19,20]$. The exponential growth phase exhibits a maximum OTR of $65-80 \mathrm{mmol} / \mathrm{L} / \mathrm{h}$ after $5 \mathrm{~h}$ of cultivation. The horizontal plateau indicates a phase of oxygen limitation. Subsequently, the sharp decrease in the OTR to a value of about $10 \mathrm{mmol} / \mathrm{L} / \mathrm{h}$ indicates the depletion of all original carbon sources. Some residual growth is attributed to the consumption of acetate as overflow metabolite (data not shown) as described in general [40,41] and in particular for TB medium [39]. In further experiments, the first preculture was harvested during its exponential growth phase after $3 \mathrm{~h}$ at an OTR of $40-50 \mathrm{mmol} /$ $\mathrm{L} / \mathrm{h}$ (arrow in Figure 2A), and it was further used for the inoculation of the second preculture.

The second preculture was cultivated in modified Wilms-MOPS mineral medium containing $0.5 \mathrm{~g} / \mathrm{L}$ glucose and $5 \mathrm{~g} / \mathrm{L}$ glycerol as carbon sources. Figure 2B illustrates that all investigated $E$. coli clones depict the same respiration behavior. After a first initial increase, the OTR slightly decreases after $3 \mathrm{~h}$ due to the depletion of the preferred carbon source glucose (dotted line in Figure 2B). Afterwards, exponential growth on glycerol results in a maximum OTR of $55-65 \mathrm{mmol} / \mathrm{L} / \mathrm{h}$ after $6.5 \mathrm{~h}$. The subsequent plummeting of the OTR to $0 \mathrm{mmol} / \mathrm{L} / \mathrm{h}$ indicates the exhaustion of all original carbon sources. Due to the defined composition of the cultivation medium, the low carbon source concentration, and the prevention of an oxygen limitation, no acetate formation was observed during the cultivation in Wilms-MOPS mineral medium (data not shown). For subsequent experiments, the second preculture was harvested during its exponential growth phase after $5 \mathrm{~h}$ at an OTR of $25-35 \mathrm{mmol} / \mathrm{L} / \mathrm{h}$ (arrow in Figure $2 \mathrm{~B}$ ), and was used for inoculating the main culture.

The investigated $E$. coli clones bear plasmids with genes encoding BSLA with different single amino acid exchanges. In this study, the plasmids had no effect on E. coli metabolism under non-inducing conditions. According to literature, the plasmid pET22b $(+)$ used here usually occurs with about 40 copies per cell [42] thus belonging to the high copy number plasmids. In our study, 25 copies per genome could be measured under noninducing conditions. In general, increased plasmid copy numbers can provoke decreasing growth rates [43-46]. Nevertheless, in comparison to E. coli BL21(DE3) not bearing any plasmid (Figure 2, Additional file 2) no effect on growth and in consequence no negative influence on metabolism were observed for the investigated clones during non-inducing cultivations in this study. This may be explained by the relatively small plasmid size which influences growth to a lesser extent than larger plasmids $[47,48]$. The small variation in the gene sequences of the studied clones had no influence on $E$. coli respiration behavior under non- 


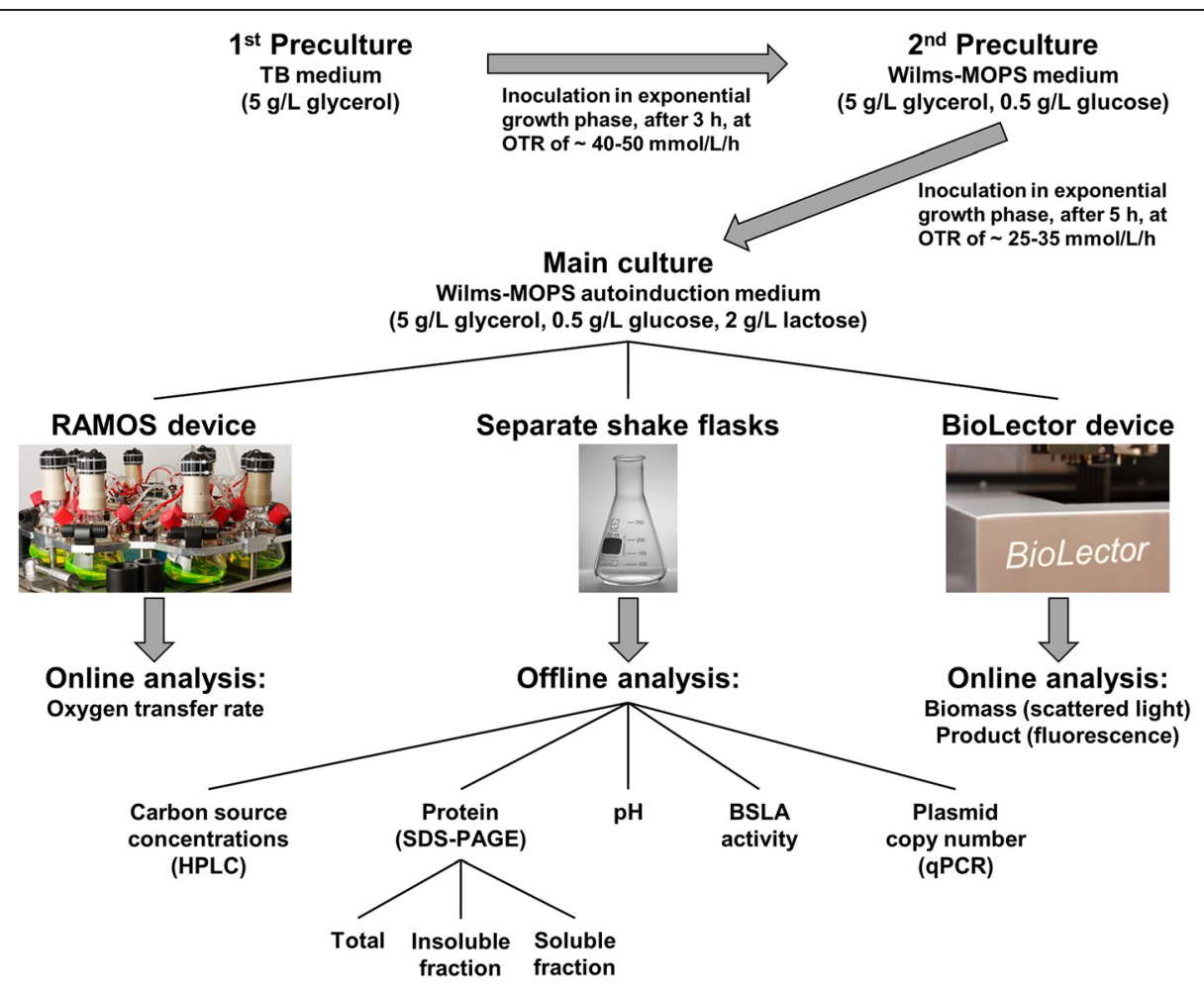

Figure 1 Overview of different cultivation steps, cultivation systems, and measured online and offline data. First preculture is performed in complex non-inducing TB medium, second preculture in non-inducing Wilms-MOPS mineral medium. Both precultures are carried out in $250 \mathrm{~mL}$ flasks in a RAMOS (Respiration Activity MOnitoring System) device. The main culture is performed in Wilms-MOPS mineral autoinduction medium in three cultivation systems in parallel: RAMOS device $(250 \mathrm{~mL}$ shake flasks), separate $250 \mathrm{~mL}$ shake flasks and 48 -well Flowerplate in a BioLector device. The RAMOS device allows an online measurement of the oxygen transfer rate (OTR) of the culture. Separate shake flasks are used for offline analysis. The BioLector device monitors the formation of biomass (scattered light intensity) and product (fluorescence).

inducing conditions. This suggests that the metabolism is not burdened, because an increase in copy number is not induced and the expression system used here is tightly controlled and not leading to any unintended recombinant protein expression as previously described for expression studies using complex media $[49,50]$.

\section{Cultivation under inducing conditions}

Influence of single amino acid exchanges and definition of two distinct types of respiration behavior

For the main cultivation under inducing conditions using lactose as inducer, the 15 investigated E. coli BL21 (DE3) clones were cultivated in Wilms-MOPS mineral autoinduction medium to determine their respiration activity under inducing conditions. Figure 3 depicts the respective OTR curves of all clones as a function of time obtained from 2-6 independent replicate experiments.

Despite a similar respiration behavior of all clones cultivated under non-inducing conditions (Figure 2), Figure 3 shows highly reproducible differences among the clones with respect to respiration under inducing conditions. In contrast, an E. coli BL21(DE3) without plasmid delivers the expected identical respiration behavior as under non-inducing conditions (Additional file 2). The differences in respiration presented in Figure 3 resemble the behavior of clones that express different recombinant proteins in complex autoinduction medium investigated by Kunze et al. [19]. To allow a better understanding of the metabolic processes during induction and protein expression, in this current study, a mineral autoinduction medium with a defined composition was used. To verify that the obtained differences in respiration (Figure 3) are not caused by the growth medium itself, in one additional experiment all 15 E. coli BL21(DE3) clones were cultivated in complex autoinduction medium. Thereby, it could be shown that differences between the clones also arise during cultivation in complex autoinduction medium (Additional file 3). After an exponential increase in OTR within the first $3.5 \mathrm{~h}$, the OTR of some clones (e.g. I12C, K23stop, S56P, G175F) further increases continuously until reaching a maximum. For other clones (e.g. A1W, F17P, G93Y, K170E) the OTR drops after a short constant phase and afterwards increases again. The clone His-LOV even shows a sharper decrease in OTR. After further $1.5 \mathrm{~h}$, another increase to its maximum OTR is observed. The differences in complex autoinduction medium, though, are less pronounced than in 


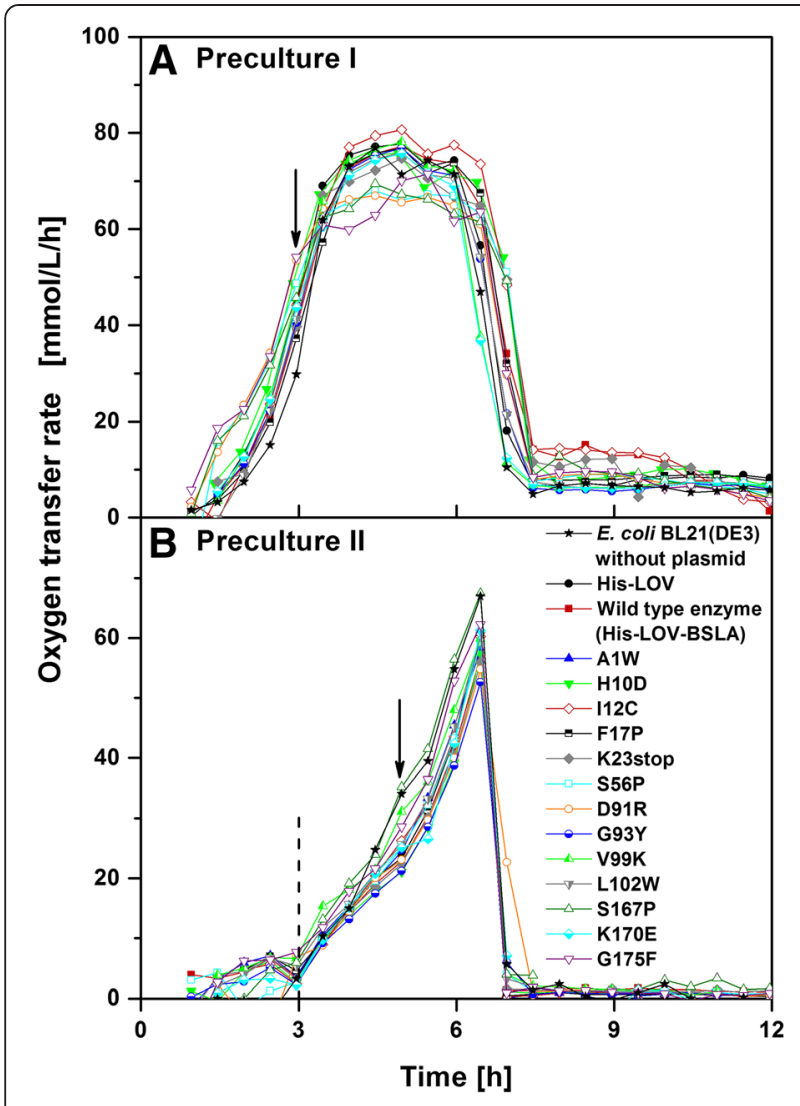

Figure 2 Precultivations of $15 \mathrm{E}$. coli BL21(DE3) clones and an E. coli BL21(DE3) control without plasmid under non-inducing conditions. Oxygen transfer rate (OTR) as a function of time for: (A) first preculture performed in complex TB medium, and (B) second preculture performed in Wilms-MOPS mineral medium. The arrows indicate the time points the cultures were harvested and used for inoculating the next cultivation step. The dotted line in (B) highlights the depletion of glucose. Cultivation conditions: $37^{\circ} \mathrm{C}, 250 \mathrm{~mL}$ flasks, filling volume $10 \mathrm{~mL}$, shaking frequency $350 \mathrm{rpm}$, and shaking diameter $50 \mathrm{~mm}$

mineral autoinduction medium. This can be explained by the fact that under the chosen cultivation conditions (equal to those in Figure 3), the cultures are oxygen limited over a wide range of the cultivation due to the very rich medium composition. In mineral autoinduction medium the differences between the investigated clones appear much clearer. Remarkably, significant differences in OTR occur even though the recombinant target proteins (BSLA) differed in just a single amino acid. These reproducible differences in the metabolic activity (Figure 3), thus, lead to the conclusion that even very small differences in the gene sequence coding for BSLA influence the host organism in quite different ways during cultivation under inducing conditions. Despite the diverse OTR patterns, the clones are classified into two types of respiration behavior (Type A and Type B) according to their maximum OTRs and cultivation durations. Even though there seems to be a continuous change between the respiration behaviors of the investigated clones, in this study the attempt for a classification is made, as this simplifies the discussion about the general differences observed. In former publications of Lee and Ramirez [18] and Kunze et al. [19] E. coli clones expressing different recombinant proteins were already classified according to growth and respiration. As Figure 3 illustrates, all clones show an initial increase in OTR due to their growth on the preferred carbon source glucose. As already noticed from second precultivations (Figure $2 \mathrm{~B}$ ), after $3 \mathrm{~h}$, the depletion of glucose leads to a small drop in the OTR, followed by a further increase to a first OTR peak after 5-6 h. The nine clones classified into respiration behavior Type A (Figure 3, white background) reach an OTR of $15-20 \mathrm{mmol} / \mathrm{L} / \mathrm{h}$, whereas the OTRs of the six clones belonging to respiration behavior Type B (Figure 3, grey background) increase up to only about $10 \mathrm{mmol} / \mathrm{L} / \mathrm{h}$. After a phase of decreasing or constant OTR of various lengths, all clones show an OTR increase until a second peak is reached at $15-20 \mathrm{mmol} / \mathrm{L} / \mathrm{h}$ (Type A) or $25-40 \mathrm{mmol} / \mathrm{L} / \mathrm{h}$ (Type B), respectively. The end of the cultivation is indicated by the sharp drop in OTR. The cultivation takes 12-17 h (Type A) or 12-13 h (Type B), respectively.

Besides the qualitative classification of the clones into two types of respiration behavior according to their OTR pattern, it was possible to quantitatively classify Type A and Type B. As illustrated in Figure 4, the ratio between integral X (from the first OTR peak to the local minimum) and integral $Y$ (from the minimum to the second peak) was calculated for all individual cultivations presented in Figure 3. As shown later, the integral $\mathrm{X}$ represents the phase of protein formation and $\mathrm{Y}$ the second growth phase on residual glycerol after lactose is depleted. The mean $\mathrm{X} / \mathrm{Y}$ ratios of all investigated clones are presented in Table 2. The $\mathrm{X} / \mathrm{Y}$ ratio of the nine clones representing respiration behavior Type $\mathrm{A}$ is in the range of 1.4-2.4, and in the range of 0.4-0.6 for the six clones belonging to respiration behavior Type B. The standard deviation varies between 0.4-7.9\%. To allow an easier classification of clones into Type A or Type B respiration behavior according to their $\mathrm{X} / \mathrm{Y}$ ratio, a critical $\mathrm{X} / \mathrm{Y}$ ratio is introduced (Table 2). All clones exhibiting a ratio greater than 1.2 can be categorized into Type A respiration behavior, whereas clones with a ratio smaller than 1.2 can be classified into Type B. This critical X/Y ratio offers an easy way to distinguish between Type $\mathrm{A}$ and Type B clones in future cultivations.

In the following, some first ideas about possible factors causing the different behavior of Type A and Type B clones will be examined. Preliminary data concerning metabolic costs for the amino acid biosynthesis, enzyme activity, plasmid copy number, formation of inclusion bodies as well as the ratio of insoluble to soluble protein will be presented and discussed. Thereby, our investigations 


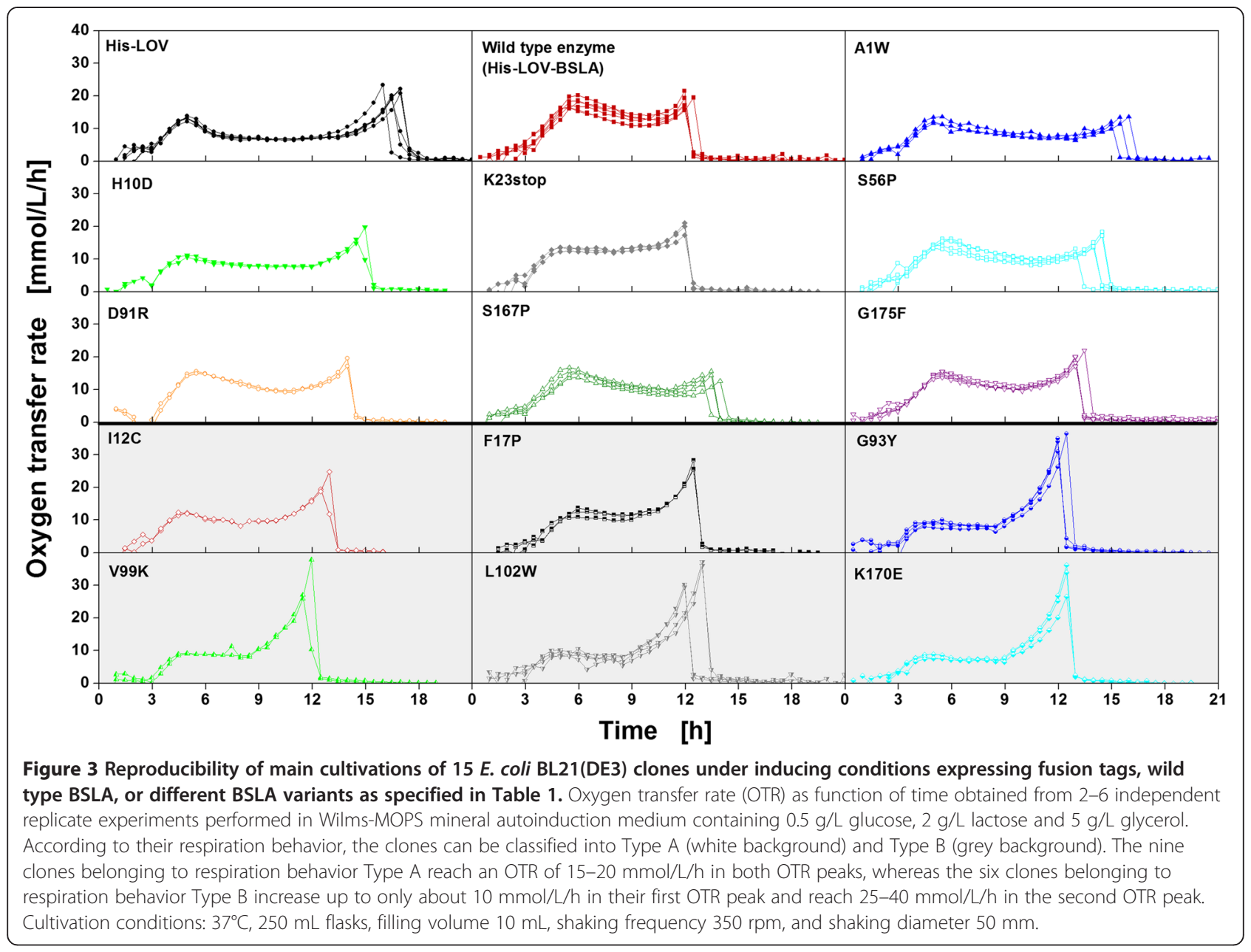

should give a first hint at possible influencing factors without yet studying all parameter in detail.

In addition to an identical host organism and expression system, all E. coli BL21(DE3) clones, except HisLOV and K23stop, express identical target proteins, that only differ in one single amino acid within the BSLA sequence (Table 1, Additional file 1). Whether the investigated clones express active (+) or inactive (-) BSLA can be recognized from the figure legend of Figure 5. In contrast to the example given by Palmen et al. [20], no cofactor is necessary here for the target protein. Moreover, differences in a stringent-like response [24-26] could be predominantly prevented due to the exchange of just one amino acid. Nevertheless, reproducible differences in growth were observed and a classification into two types of respiration behavior was possible.

To evaluate if increased or decreased energetic costs in amino acid biosynthesis cause the two different types of respiration behavior (Type A and Type B), all amino acid exchanges were examined separately according to Akashi and Gojobori [22]. In Type A as well as in Type $\mathrm{B}$ clones, amino acids causing high energetic costs were replaced by amino acids causing lower costs (e.g. H10D for Type A, and F17P for Type B) and inexpensive amino acids were replaced by expensive ones (e.g. A1W for Type A, and L102W for Type B). Hence, metabolic costs of the amino acid biosynthesis could be excluded as a reason for the two presented types of respiration behavior. The change in respiration activity of the different clones caused by a lack of a certain amino acid is also precluded e.g. by the clones S56P and F17P. In both cases, the wild type amino acid has been substituted by proline $(\mathrm{P})$, resulting in an equally increased proline demand. Nevertheless, these two clones belong to different types of respiration behavior. Thus, a lack of proline cannot explain the different OTR patterns.

\section{Comparison of respiration behavior Types $A$ and $B$, and correlations between OTR, biomass and product formation}

The differences between Type A and Type B clones were further examined by determination of biomass (via scattered light) and product formation (via fluorescence) during cultivation in Wilms-MOPS mineral autoinduction medium. A comparison of OTR (using RAMOS), 


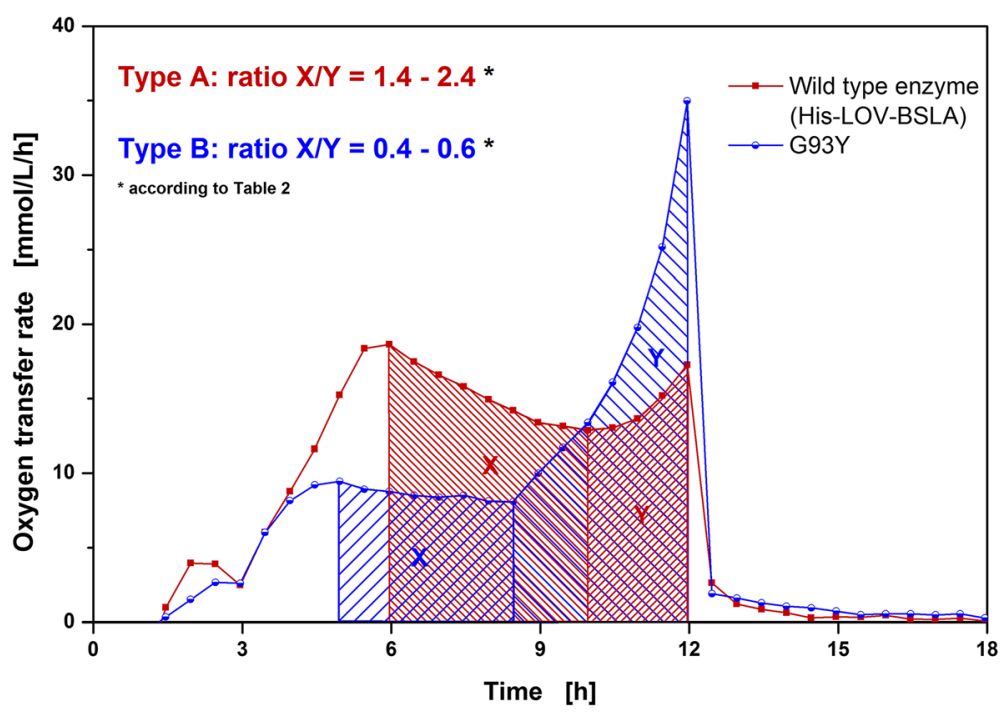

Figure 4 Quantitative classification of 15 E. coli BL21(DE3) clones into Type A and Type B according to their respiration behavior. Comparison of the respiration behavior (oxygen transfer rate) as function of time of Type $A$ and Type $B$ clones calculating the ratio between integral $X$ (from first OTR peak to minimum) and integral $Y$ (from minimum to second peak). Integral $X$ represents the phase of protein formation; integral $Y$ represents the second growth phase on residual glycerol. According to Table 2, the ratio $X / Y$ is in the range of 1.4-2.4 for the nine clones specified in Figure 3 belonging to Type A, and in a range of 0.4-0.6 for the six clones belonging to Type B.

biomass and product formation (using BioLector) of the investigated clones is shown in Figure 5 (Type A: white background; Type B: grey background). In this way, two small-scale online monitoring systems are combined with one another. The reproducibility of biomass and product formation with presentation of measured data points, arithmetic mean and standard deviation is depicted in Additional files 4 and 5, respectively.

As shown in Figure 5, the biomass signal (scattered light intensity) of Type A and B clones increases exponentially until $5-7 \mathrm{~h}$ of cultivation, followed by a further linear increase. The time point of the transition from exponential to linear growth roughly correlates with the first OTR peak. Similarly, the duration of the linear increase correlates with the phase of decreasing or constant OTR. At the transition point from exponential to linear growth, clones from Type A attain a biomass signal (scattered light intensity) of 20-40 a.u., while Type B clones show lower biomass signals (scattered light intensities) from 10-30 a.u. This is in good agreement with the height of the first OTR peak, which is 15-20 mmol/L/h for Type A clones, and $10 \mathrm{mmol} / \mathrm{L} / \mathrm{h}$

Table 2 X/Y ratio of Type A and Type B clones

\begin{tabular}{llllll}
\hline Type A clone & Arithmetic mean X/Y ratio & Standard deviation [\%] & Type B clone & Arithmetic mean X/Y ratio & Standard deviation [\%] \\
\hline His-LOV & 1.7 & 7.1 & I12C & 0.6 & 0.5 \\
$\begin{array}{l}\text { Wild type enzyme } \\
\text { (His-LOV-BSLA) }\end{array}$ & 2.2 & 4.6 & F17P & 0.6 & 3.6 \\
A1W & 2.2 & 7.9 & G93Y & 0.5 & 6.7 \\
H10D & 1.4 & 2.0 & V99K & 0.5 & 0.4 \\
K23stop & 1.5 & 2.9 & L102W & 0.4 & 4.5 \\
S56P & 1.9 & 3.8 & K170E & 0.4 & 3.3 \\
D91R & 1.4 & 2.5 & & & \\
S167P & 2.4 & 7.5 & & & \\
G175F & 1.4 & 1.8 & & & \\
Type A & $\mathbf{1 . 4 - 2 . 4}$ & & Type B & $\mathbf{0 . 4 - 0 . 6}$ \\
Type A & $>\mathbf{1 . 2}$ & & Type B* & $<\mathbf{1 . 2}$ \\
\hline
\end{tabular}

Ratio between integral $X$ (representing protein production phase) and integral $Y$ (representing second growth phase) determined for the 15 investigated $E$. coli $\mathrm{BL} 21$ (DE3) clones according to Figure 4. For each clone, the $\mathrm{X} / \mathrm{Y}$ ratio was calculated for all individual cultivations presented in Figure 3 . The arithmetic mean as well as the standard deviation (in \%) are presented.

${ }^{*}$ Critical $\mathrm{X} / \mathrm{Y}$ ratio for simplified classification between Type $\mathrm{A}$ and Type B clones. 


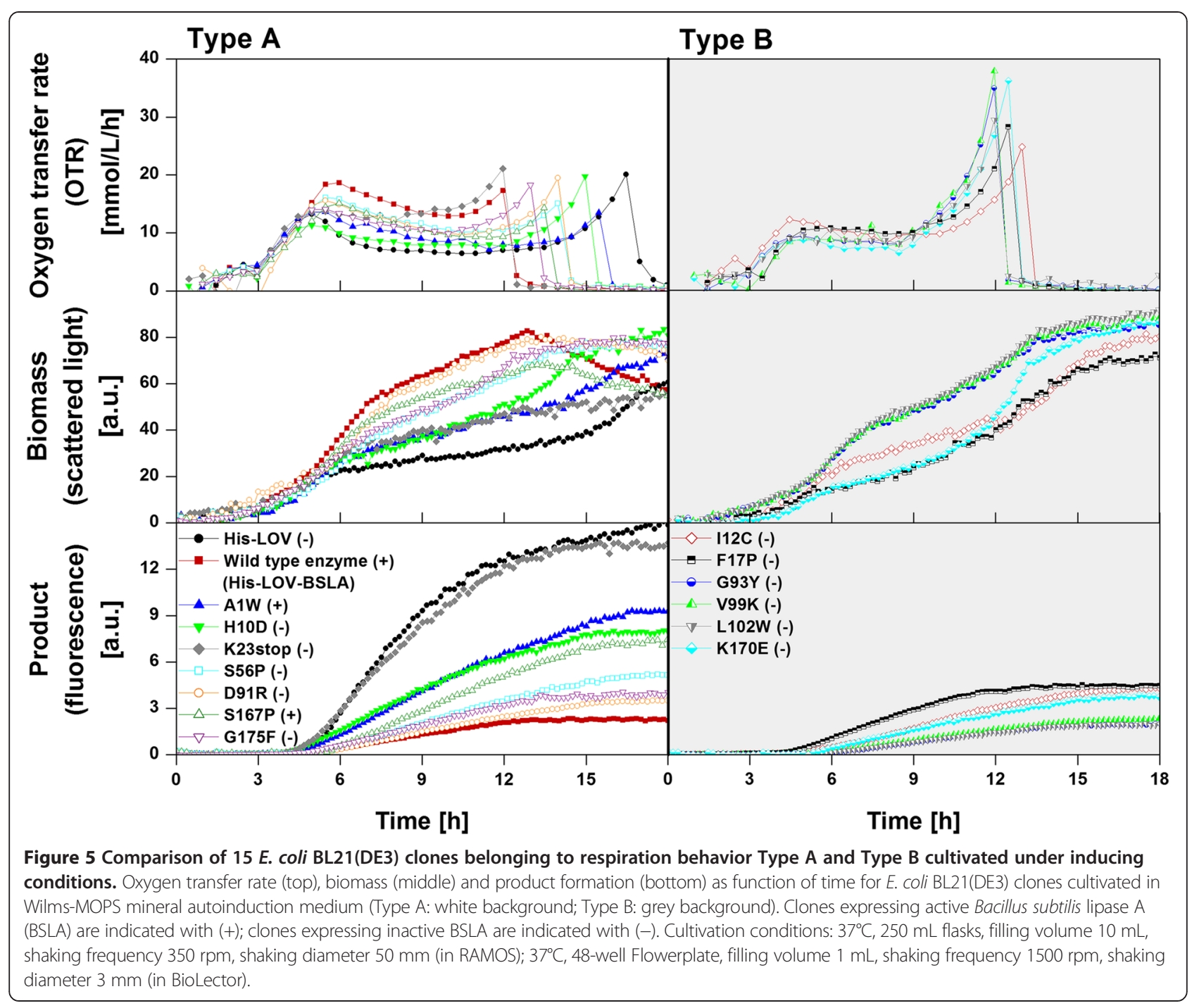

for Type B clones. With the final increase in OTR, most clones exhibit another significant increase in the biomass formation. A slight decrease of biomass formation at the end of the cultivation is only observed for a few clones and can be attributed to morphological changes of the cells [51-53]. The final biomass signal (scattered light intensity) for Type A clones ranges from 50-80 a.u., and for Type $\mathrm{B}$ clones ranges from 70-90 a.u. Hence, Type B clones showing a strong OTR increase in the second half of cultivation obtain higher final biomass signals.

As also shown in Figure 5, the product formation of all investigated clones starts after 5-6 h, correlating perfectly with the first OTR peak and with the transition from exponential to linear biomass increase. Strong product formation is obtained during the phase of decreasing or constant OTR and linear biomass increase. With the final increase in OTR and biomass signal (scattered light intensity) the product formation rate decreases.
The final product fluorescence signal of Type B clones ranges from 1-4.5 a.u., whereas Type A clones produce generally higher amounts of between 2-9 a.u. It has to be considered that the two clones His-LOV and K23stop showing the highest product fluorescence signals (15 a.u. and 12 a.u., respectively) produce shorter target proteins than all other clones (Table 1, Additional file 1) and, therefore, have to be regarded as reference clones. Generally, clones belonging to respiration behavior Type A produce higher amounts of target protein than Type B clones. Type A clones with higher product formation usually result in lower biomass signals. On the other hand, Type B clones showing a strong OTR increase in the second half of the cultivation and a higher biomass formation produce less target protein. Thus, our results agree with the inverse correlation of product formation and growth that was already reported before $[54,55]$. In agreement with Kunze et al. [19], a correlation between the progress of the OTR as function of time and the product formation could be 
observed. While phases of decreasing or constant OTR resulted from high product formation, an exponential increase in OTR indicated undisturbed cell growth.

The figure legend of Figure 5 also indicates whether the investigated clones express active $(+)$ or inactive $(-)$ BSLA. Twelve out of fifteen clones expressed inactive BSLA. A correlation between respiration behavior and enzyme activity could not be found. Clones producing inactive enzymes were found in both, Type A and Type $B$, groups, whereby in Type B only inactive enzyme was expressed. A correlation between expressed protein and functionality cannot be found, either. From full-length products, the active variants A1W and S167P are produced in relatively high amounts (9 a.u. and 6 a.u., respectively), whereas the active wild type enzyme is produced in a very low amount (2 a.u.). Furthermore, the variant H10D is produced in a relatively high amount (8 a.u.) even though the expressed protein is inactive.

For a quantitative analysis of the relation between respiration activity and product formation, Figure 6 shows a correlation of the final product fluorescence signals and the cultivation duration (duration of active respiration). The insert illustrates how the cultivation duration of the particular E. coli clones (until the last peak of the OTR) was determined. For the calculation of the regression line, all clones expressing a full-length product as specified in Table 1 and Figure 1 were taken into account. The two clones expressing shorter products (HisLOV and K23stop) were not considered and, therefore, were marked in parentheses in the graph. Even though the investigated clones belong to two different types of respiration behavior, a correlation between the final product fluorescence signals and the cultivation duration was found $\left(R^{2}=0.78\right)$. Longer cultivation durations lead to an enhanced product formation. This agrees with the fact that growth is reduced in case of enhanced product formation, and that with equal amounts of available carbon and energy sources, slower growth results in prolonged cultivation durations.

\section{Characterization of Type $A$ and $B$ clones, and definition of five characteristic cultivation phases}

Fermentations were further analyzed by an additional cultivation performed in Wilms-MOPS mineral autoinduction medium with parallel offline analysis (Figure 7). In order to measure the carbon source concentrations, the plasmid copy number related to the number of genome copies, the $\mathrm{pH}$-value, and the target protein content, samples were taken from conventional Erlenmeyer flasks. The measurements were performed for four clones as specified in Figure 7A as examples. Three of those four clones belong to the respiration behavior Type A (white background), while one belongs to the respiration behavior Type B (grey background). Besides the clone expressing the wild type enzyme which is regarded as reference clone, the Type A clones S56P and S167P with an identical amino acid exchange at different positions of BSLA were investigated to obtain information about possible amino acid position effects. Furthermore, the clone K170E exemplified Type B clones. In addition to the characteristic growth parameters (Figure 7A), Figure 7B depicts a SDS-PAGE analysis of the soluble and Figure $7 \mathrm{C}$ of the insoluble protein fractions.

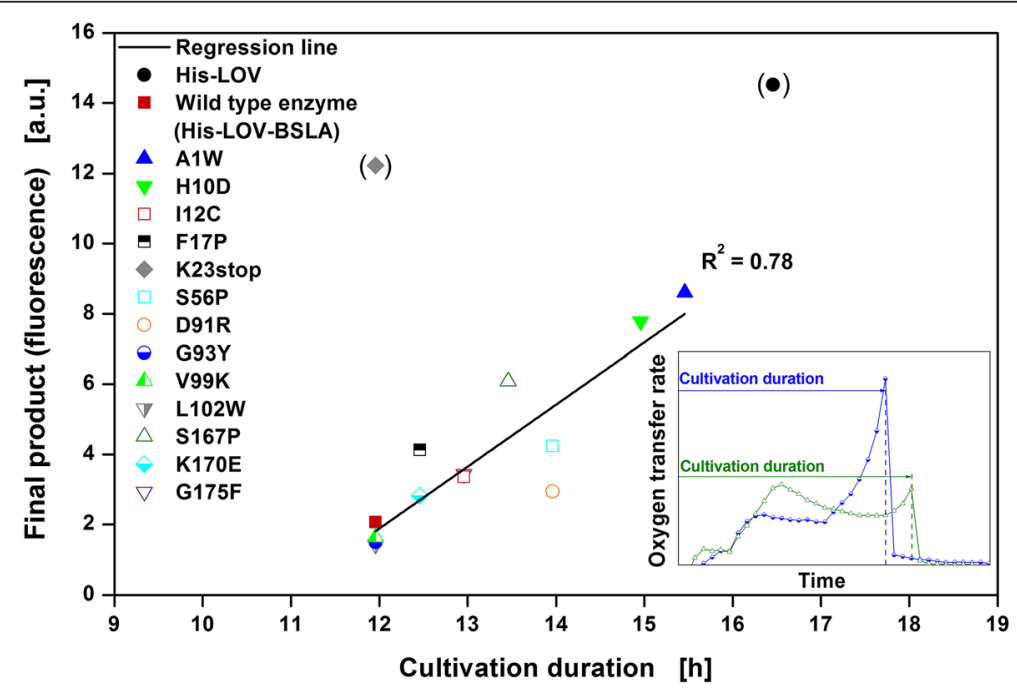

Figure $\mathbf{6}$ Correlation of final product fluorescence signal and cultivation duration. Final product fluorescence signal of 15 E. coli BL21(DE3) clones as function of the cultivation duration (until the last peak of the oxygen transfer rate, as shown in the insert). Calculated regression line $\left(R^{2}=0.78\right)$ is based on all clones expressing a full-length target protein as specified in Table 1 and Additional file 1. Shorter products (His-LOV and K23stop) are not considered for the calculation and are marked in parentheses. 


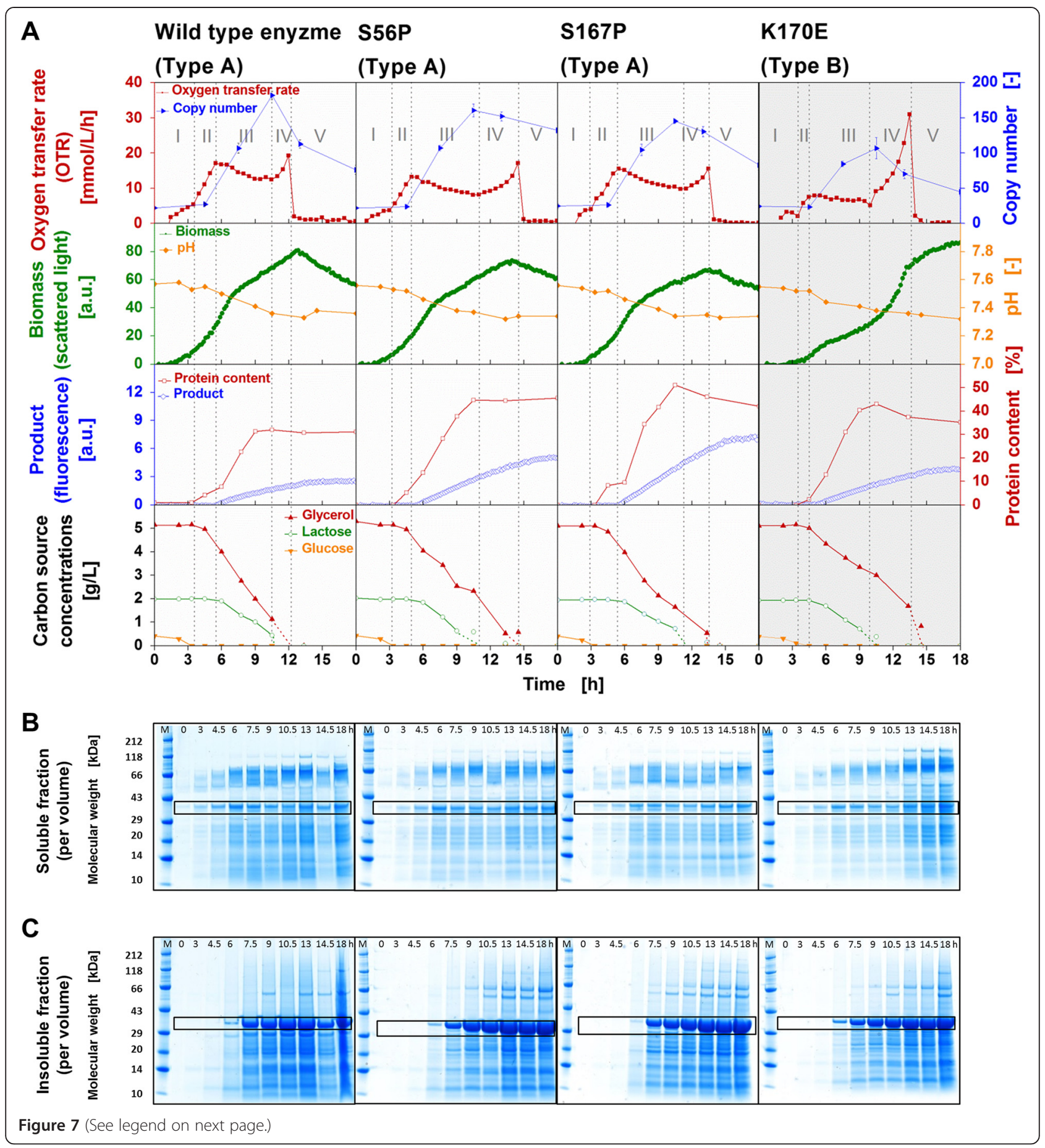


(See figure on previous page.)

Figure 7 Detailed characterization of four E. coli BL21(DE3) clones belonging to respiration behavior Type A and Type B cultivated under inducing conditions. Characterization of four E. coli BL21(DE3) clones belonging to respiration behavior Type A (expressing wild type BSLA and variants S56P and S167P) and respiration behavior Type B (BSLA variant K170E) during the cultivation in Wilms-MOPS mineral autoinduction medium. (A) Characteristic growth parameters: oxygen transfer rate (OTR), biomass and product formation, carbon source concentrations, copy number of plasmid per genome, $\mathrm{pH}$-value, and protein content of the target protein per total protein of the cell. Type A: white background; Type B: grey background. The five cultivation phases (I-V) are identified by the OTR curves and are separated by the vertical grey dotted lines. (I) increase in OTR due to growth on glucose, the depletion of glucose corresponds with a small OTR drop (first grey dotted line); (II) increase in OTR to first peak (second grey dotted line) due to growth on glycerol; (III) slightly decreasing or constant OTR, respectively, due to product formation on lactose with parallel consumption of glycerol, the depletion of lactose roughly corresponds with the minimum of the OTR (third grey dotted line); (IV) increase in OTR to second peak (forth grey dotted line) due to growth on residual glycerol; ( $V$ end of cultivation, the depletion of glycerol roughly corresponds with the sharp drop in OTR. (B) SDS-PAGE analysis showing soluble protein per sample volume, and (C) SDS-PAGE analysis showing insoluble protein per sample volume after 0, 3, 4.5, 6, 7.5, 9, 10.5, 13, 14.5 , and $18 \mathrm{~h}$ of cultivation (target protein band is framed, $\mathrm{M}=$ protein marker). Cultivation conditions: $37^{\circ} \mathrm{C}, 250 \mathrm{~mL}$ flasks, filling volume $10 \mathrm{~mL}$, shaking frequency $350 \mathrm{rpm}$, shaking diameter $50 \mathrm{~mm}$ (in RAMOS); $37^{\circ} \mathrm{C}$, 48-well Flowerplate, filling volume $1 \mathrm{~mL}$, shaking frequency $1500 \mathrm{rpm}$, shaking diameter $3 \mathrm{~mm}$ (in BioLector).

$E$. coli clone expressing the wild type BSLA As presented in Figure 7A, during the first phase of the cultivation (I), the clone expressing wild type BSLA shows an initial increase in OTR and biomass signal due to growth on glucose. Its depletion corresponds with a small drop in the OTR after $3 \mathrm{~h}$ (first grey dotted line). In the second cultivation phase (II), further growth on glycerol occurs until $5 \mathrm{~h}$ accompanied by an increase in the OTR up to its first peak at $17 \mathrm{mmol} / \mathrm{L} / \mathrm{h}$. In this phase, no product formation is observed by fluorescence measurement. However, a small increase in the target protein content is found after $4.5 \mathrm{~h}$ by densitometric analysis. At the end of the second cultivation phase (second grey dotted line), the target protein production phase is initiated, and shortly after, the transition point from exponential to linear biomass formation occurs. Cultivation phase three (III) is characterized by a strong increase in product fluorescence signal and protein content with parallel consumption of the inducing compound lactose and the energy rich carbon source glycerol. As a result, the OTR decreases from its first peak to a minimum of $12 \mathrm{mmol} / \mathrm{L} / \mathrm{h}$ after $10.5 \mathrm{~h}$, and biomass growth is linear. Corresponding to the reduced growth rate, a strong increase in the plasmid copy number can be detected. Such correlation was previously described in literature $[9,45,56]$. At the end of the third cultivation phase (third grey dotted line), the inducing compound lactose becomes depleted, correlating with a maximum target protein content of about $31 \%$ and a maximum plasmid copy number of 182. During the fourth cultivation phase (IV), the residual glycerol is consumed leading to a small OTR increase up to a second peak of about $19 \mathrm{mmol} / \mathrm{L} / \mathrm{h}$. A further rise in biomass signal (scattered light intensity) up to its maximum (80 a.u.), a slight increase in the product formation, as well as a decrease in the plasmid copy number are observed. Glycerol depletion after $12 \mathrm{~h}$ (fourth grey dotted line) then results in a sharp drop in the OTR, a constant product fluorescence signal of 2.6 a.u. and a further decrease in the plasmid copy number. The monitored decrease in biomass formation is attributed to a change in the cell morphology [51-53]. In general, the optical measuring signals of biomass and product formation determined using the BioLector device shall only be considered during the phase of active respiration. Thereafter, factors like evaporation, cell lysis, or morphological changes can influence the measuring signals [51-53]. Because of the well-buffered medium, the $\mathrm{pH}$-value decreases only slightly from 7.5 to 7.3 during the entire cultivation. Furthermore, no acetate is formed (data not shown), due to the applied medium composition and cultivation conditions.

Based on the obtained online and offline data, the cultivation can generally be divided into five characteristic phases: (I) growth on glucose, (II) growth on glycerol, (III) product formation on lactose with parallel consumption of glycerol as energy source, (IV) growth on residual glycerol, (V) depletion of all original carbon sources and end of cultivation. Thus, without laborious offline analyses, these cultivation phases can be identified via online monitoring of the OTR progress as function of time with the RAMOS device.

E. coli clones S56P and S167P Fermentation of Type A clones S56P and S167P (Figure 7A) reveals the same five characteristic cultivation phases. Whereas the first OTR peak of S167P is the same as for the clone expressing wild type BSLA, it is lower for S56P (13 $\mathrm{mmol} / \mathrm{L} / \mathrm{h})$. With regard to the second peak, both clones reach a slightly lower maximum value. In comparison to the clone expressing wild type BSLA, the cultivation duration of S56P and S167P is somewhat longer (15 h and $14 \mathrm{~h}$, respectively), while the biomass formation is reduced (maximum scattered light intensity of 73 a.u. and 66 a.u., respectively). For both clones, a higher protein formation is detected. S56P reaches a product fluorescence signal of 5 a.u., resulting in a target protein content of $45 \%$, whereas clone S167P attains a product fluorescence signal of 7 a.u. and a target protein content of $51 \%$. The maximum plasmid copy number for S56P and S167P is reduced to 160 and 145, respectively. 
The clones S56P and S167P contain identical amino acid exchanges within BSLA sequence, but at different positions. Even though S56P expresses enzymatically inactive and S167P active BSLA (Figure 5), the fermentation progress of both clones is roughly the same. As a result, neither the position of the amino acid exchange in the protein nor the enzyme activity influence the cultivation progress.

E. coli clone $\mathrm{K} 170 \mathrm{E}$ The clone $\mathrm{K} 170 \mathrm{E}$ belongs to the respiration behavior Type B. Even if the OTR progress as function of time is different compared to that of Type $\mathrm{A}$, the same cultivation phases have been identified (Figure 7A). A further confirmation of the five cultivation phases for two more Type B clones is presented in the supplementary data (Additional file 6). Whereas the first cultivation phase (I) with a similar growth rate and OTR progress is comparable to those of Type A clones, the second phase (II) is much shorter. Consequently, the first OTR peak after $4.5 \mathrm{~h}$ reaches only $8 \mathrm{mmol} / \mathrm{L} / \mathrm{h}$. The biomass signal at the transition point from exponential to linear growth with a scattered light intensity of only 15 a.u. is much lower than that of the Type A clones (66-80 a.u.). No product formation was detected in this phase. Due to the shorter second cultivation phase, the third cultivation phase (III) is initiated earlier. Up to this point, not only the biomass concentration, but also the amount of consumed glycerol is lower. During the third phase (III), the OTR remains nearly constant at 8$5 \mathrm{mmol} / \mathrm{L} / \mathrm{h}$ until $10 \mathrm{~h}$, correlating with a linear increase in the biomass signal. This initiates the product formation, and an increase in the protein content. One remarkable difference between Type A and Type B clones is the consumption of glycerol during this phase. Type $\mathrm{A}$ clones consume a relatively high amount of glycerol in parallel with lactose, thereby leading to a low residual glycerol concentration of $1-2 \mathrm{~g} / \mathrm{L}$ at the end of cultivation phase three (third grey dotted line). In contrast, the residual glycerol concentration of clone $\mathrm{K} 170 \mathrm{E}$ is about twice as much $(3 \mathrm{~g} / \mathrm{L})$ due to the higher glycerol concentration at the beginning of the this phase and the reduced parallel glycerol consumption. Accordingly, the high amount of residual glycerol causes an exponential increase in OTR (up to $31 \mathrm{mmol} / \mathrm{L} / \mathrm{h}$ ) and biomass signal (scattered light intensity, up to 92 a.u.) in the fourth cultivation phase (IV). The final product fluorescence signal is 3.9 a.u., and the maximum target protein content is $43 \%$. The curve of the $\mathrm{pH}$-value is the same as that of the other clones and no acetate formation can be detected (data not shown). Another difference between Type B clone K170E and the Type A clones is a reduced maximum copy number of 106 (Type B) compared to 145-182 (Type A) even though the curve of the plasmid copy number as a function of time is qualitatively similar. One possible explanation is that the metabolic burden is initiated at an earlier stage, thus, preventing a further increase of the plasmid copy number. Another probable explanation is an enhanced plasmid loss $[48,57,58]$. However, plasmid-free cells in general occur only rarely as long as the copy number remains high [58]. To evaluate whether the plasmid stability varied between Types A and B, the plasmid loss was quantified by selective plate counts for both types (data not shown). Thereby, it could be excluded that cells without plasmids overgrew cells containing plasmids.

Not only the maximum values and the progress of the plasmid copy number, but also the correlation between copy number and growth behavior have to be considered when comparing Type A and Type B clones. As already mentioned above, the third cultivation phase starts earlier for the Type B than for Type A clones. As a result, the induction of the protein expression, as well as the increase of the copy number start earlier. In general, both, recombinant protein expression as well as an increase of the copy number lead to a burden on the host's metabolism which is indicated by a decreasing growth rate and a decreasing or constant OTR. Probably because of the reduced biomass at the beginning of the third cultivation phase, the maximum plasmid copy number is lower for K170E compared to Type A clones. With the end of the induction phase, the copy number and as result the metabolic burden decrease. Consequently, growth on residual glycerol is again possible, leading to the characteristic OTR pattern of Type B clones.

The only difference of the investigated clones consists in a single amino acid exchange within the recombinant lipase. As consequence of these exchanges, the initial growth in the second cultivation phase (II) is reduced for clones categorized in Type B. All correlations and effects on recombinant protein expression, progress of copy number, and the diverse consumption pattern of glycerol described above can be regarded as consequence of these small differences between the investigated clones.

SDS-PAGE analysis showing soluble and insoluble protein fractions After investigating the characteristic growth parameters (Figure 7A), SDS-PAGE analysis of soluble (Figure 7B) and insoluble (Figure $7 \mathrm{C}$ ) protein fractions was performed. The aim was to investigate if the ratio between soluble and insoluble protein fractions may cause the different respiration behavior of Type A and $\mathrm{B}$ clones. Equally for all clones, protein bands in the soluble fraction can be detected after $4.5 \mathrm{~h}$. This correlates with the onset of product formation after $5 \mathrm{~h}$ (Figure 7A). Then, the amount of protein increased until 6 to $7.5 \mathrm{~h}$ and remained constant until the end of the cultivation. The SDS-PAGE analysis of the insoluble 
protein fraction shows traces of target protein after $6 \mathrm{~h}$. Subsequently, an enormous increase in insoluble protein was observed until the end of the cultivation. These results suggest that protein expressed at the beginning of the production phase was folded correctly and remained in the soluble protein fraction. With increasing biosynthesis of the target proteins, a correct folding may increasingly be impeded and incorrectly folded proteins accumulate as inclusion bodies. As a result, the recombinant protein production can trigger various stress responses, e.g. heat-shock-like responses [24,59,60]. Inclusion bodies mainly consist of the recombinant protein, however, co-precipitation during the process of inclusion body preparation causes certain amounts of cellular protein to be included [61-63]. Beside insoluble cell proteins, this could also be an explanation for the additional protein bands shown here (Figure 7C). Besides protein overexpression, the histidine tag present in all target proteins might also promote the formation of inclusion bodies [64]. A previously described effect of the copy number on the rate of product accumulation [63] was not observed in our investigations. The four clones (Figure 7) show different maximum copy numbers but very similar protein contents in the soluble and insoluble protein fractions. Since the ratio of insoluble to soluble protein (Table 3 ) was roughly the same for all clones, this factor could be eliminated as a reason for the different respiration behaviors of Type A and Type B clones.

\section{Conclusions}

In this study, the influence of single amino acid exchanges in heterologous enzyme on protein production and metabolic activity of the respective expression host $E$. coli BL21(DE3) was investigated. Therefore, 15 E. coli clones expressing fusion tags, wild type lipase, or different

Table 3 Ratio of insoluble to soluble protein fraction

\begin{tabular}{lllll}
\hline Time & $\begin{array}{l}\text { Wild type enzyme } \\
\text { (His-LOV-BSLA) }\end{array}$ & S56P & S167P & K170E \\
\hline $\mathbf{0 . 0} \mathbf{~ h}$ & 0.0 & 0.0 & 0.0 & 0.0 \\
$\mathbf{3 . 0} \mathbf{~ h}$ & 0.0 & 0.0 & 0.0 & 0.0 \\
$\mathbf{4 . 5} \mathbf{~ h}$ & 0.0 & 0.0 & 0.0 & 0.0 \\
$\mathbf{6 . 0} \mathbf{~ h}$ & 1.0 & 1.0 & 0.8 & 1.0 \\
$\mathbf{7 . 5} \mathbf{~ h}$ & 3.6 & 1.9 & 2.1 & 2.3 \\
$\mathbf{9 . 0} \mathbf{~ h}$ & 4.4 & 4.5 & 3.1 & 3.8 \\
$\mathbf{1 0 . 5} \mathbf{~ h}$ & 4.1 & 4.0 & 4.1 & 4.1 \\
$\mathbf{1 3 . 0} \mathbf{~ h}$ & 4.4 & 4.2 & 4.2 & 4.1 \\
$\mathbf{1 4 . 5} \mathbf{~ h}$ & 3.1 & 3.0 & 3.9 & 3.8 \\
$\mathbf{1 8 . 0 ~} \mathbf{~ h}$ & 3.8 & 3.4 & 3.3 & 3.5 \\
\hline
\end{tabular}

Ratio of insoluble to soluble protein fraction determined from TotalLab TL100 software analyzing the relative peak area of the respective protein bands. Ratios are calculated for four E. coli BL21(DE3) clones presented in Figure 7. lipase variants were compared during cultivation under non-inducing and inducing growth conditions.

As a result, no differences in respiration activity among the 15 clones were obtained under non-inducing conditions. Under inducing conditions, however, even small variations in the amino acid sequence of the target protein led to strong, highly reproducible differences in respiration activity and target protein production. A quantitative evaluation of the OTR as a function of time allowed the classification of the clones into two types of respiration behavior named Type A and Type B. With respect to the OTR curves, five characteristic cultivation phases could be identified, providing information about the time points of the depletion of the different carbon sources as well as about biomass and product formation. While phases of constant or decreasing OTR indicate strong protein production, an exponential increase in OTR occurs due to undisturbed $E$. coli cell growth. In general, clones belonging to the respiration behavior Type A were identified as clones with higher product formation, whereas clones belonging to Type B showed stronger biomass formation. Furthermore, a positive correlation between final product fluorescence signal and cultivation duration was observed.

Metabolic costs for the amino acid biosynthesis, enzyme activity, plasmid copy number, formation of inclusion bodies as well as the ratio of insoluble to soluble protein were investigated as potential factors causing the observed patterns of respiration behavior. So far, the shorter initial growth phase of Type B clones and its impact on biomass and copy number seem to have an influence. However, no particular factor could yet be identified as being exclusively responsible. Therefore, the influence of codon usage, mRNA content, as well as metabolome data are currently investigated since they might provide a deeper understanding of the underlying phenomena.

This study has proven that small variations in the gene sequence resulting in the exchange of just a single amino acid in a recombinant protein in $E$. coli influence the metabolic burden of the expression host during protein production. The two applied small-scale online monitoring systems (Respiration Activity MOnitoring Systems (RAMOS) and BioLector) allow the real-time detection of even smallest differences in respiration activity, biomass and protein production in the $E$. coli clones investigated. This study underscores the importance of parallel online monitoring systems to unveil the relevance of single amino acid exchanges for the expression of a recombinant protein.

\section{Methods}

Microorganism and target protein

Escherichia coli DH5 $\alpha$ was used for cloning and amplification. 
All cultivation experiments were conducted with $E$. coli BL21(DE3), containing the plasmid pET22b(+) (Novagen, Merck, Germany) with genes encoding different Bacillus subtilis lipase A (BSLA) [36] variants and also including a N-terminal $\mathrm{His}_{6}$ tag and a flavin-based fluorescent protein (FbFP) derived from the Light, Oxygen, Voltage (LOV) domain of the Bacillus subtilis YtvA photoreceptor (LOV tag) [37,38] (Table 1, Additional file 1). The amino acid exchanges within BSLA were chosen randomly and distributed over the entire amino acid sequence.

\section{Site directed mutagenesis}

The mutations of the gene encoding BSLA were introduced by site directed mutagenesis. Polymerase chain reactions (PCR) were carried out with the modified SPRINP method of Edelheit et al. [65]. The amplification was carried out in two separate $25 \mu \mathrm{L}$ reactions with each 10-50 ng of template, $0.2 \mathrm{pM}$ of either the forward or reverse primer (synthetized by eurofins MWG Operon, Germany), $0.2 \mathrm{mM}$ dNTPs, 3\% DMSO (v/v) and $1 \mathrm{U}$ of Phusion high fidelity DNA polymerase in Phusion GC-buffer containing $7.5 \mathrm{mM} \mathrm{MgCl}_{2}$ (Thermo Scientific, Germany). The PCR conditions were as follows: initial denaturation at $98^{\circ} \mathrm{C}$ for $10 \mathrm{~min}$ followed by 23 cycles of $98^{\circ} \mathrm{C}$ for $1 \mathrm{~min}, 55^{\circ} \mathrm{C}$ for $1 \mathrm{~min}$ and $68^{\circ} \mathrm{C}$ for $3.5 \mathrm{~min}$ followed by a final elongation step at $68^{\circ} \mathrm{C}$ for $7 \mathrm{~min}$. The PCR was paused after 5 cycles to combine the forward and reverse primer reaction and then was continued for the remaining 18 cycles. Template DNA was removed with $30 \mathrm{U} D p n \mathrm{I}$ at $37^{\circ} \mathrm{C}$ for $16 \mathrm{~h}$. The reaction was stopped at $75^{\circ} \mathrm{C}$ for $15 \mathrm{~min}$ followed by PCR purification (Analytik Jena, Germany). An aliquot of $1 \mu \mathrm{L}$ was transformed into $E$. coli DH5 $\alpha$ electrocompetent cells and plated onto selective Lysogeny Broth (LB) [66] agar plates, incubated overnight at $37^{\circ} \mathrm{C}$. Positive transformants were sequenced by eurofins MWG Operon (Germany) to ensure successful mutagenesis. For subsequent expression experiments, the constructed plasmids carrying the different mutations (Table 1) were isolated, transformed into competent E. coli BL21(DE3) cells and preserved in 15\% (w/w) glycerol at $-80^{\circ} \mathrm{C}$.

\section{Growth media}

\section{Non-inducing media}

For growth under non-inducing conditions, two different media were used. The first precultivation applied complex Terrific Broth (TB) [67] medium consisting of $12 \mathrm{~g} / \mathrm{L}$ tryptone, $24 \mathrm{~g} / \mathrm{L}$ yeast extract, $12.54 \mathrm{~g} / \mathrm{L} \mathrm{K}_{2} \mathrm{HPO}_{4}, 2.3 \mathrm{~g} / \mathrm{L}$ $\mathrm{KH}_{2} \mathrm{PO}_{4}$ and $5 \mathrm{~g} / \mathrm{L}$ glycerol (all ingredients from Roth, Germany) dissolved in water. The $\mathrm{pH}$-value was $7.2 \pm 0.2$ without adjustment. The second precultivation was carried out in modified Wilms-MOPS mineral medium according to Wilms et al. [68] that consisted of $5 \mathrm{~g} / \mathrm{L}$ glycerol, $0.5 \mathrm{~g} / \mathrm{L}$ glucose, $5 \mathrm{~g} / \mathrm{L}\left(\mathrm{NH}_{4}\right)_{2} \mathrm{SO}_{4}, 0.5 \mathrm{~g} / \mathrm{L} \mathrm{NH} \mathrm{NH}_{4} \mathrm{Cl}$ $3 \mathrm{~g} / \mathrm{L} \mathrm{K}_{2} \mathrm{HPO}_{4}, 2 \mathrm{~g} / \mathrm{L} \mathrm{Na}_{2} \mathrm{SO}_{4}, 41.85 \mathrm{~g} / \mathrm{L}$ (N-Morpholino)propanesulfonic acid (MOPS), $0.5 \mathrm{~g} / \mathrm{L} \mathrm{MgSO}_{4} \cdot 7 \mathrm{H}_{2} \mathrm{O}$, $0.01 \mathrm{~g} / \mathrm{L}$ thiamine hydrochloride, $0.1 \mathrm{~g} / \mathrm{L}$ ampicillin, $1 \mathrm{~mL} /$ $\mathrm{L}$ trace element solution $\left[0.54 \mathrm{~g} / \mathrm{L} \mathrm{ZnSO}_{4} \cdot 7 \mathrm{H}_{2} \mathrm{O}, 0.48 \mathrm{~g} / \mathrm{L}\right.$ $\mathrm{CuSO}_{4} \cdot 5 \mathrm{H}_{2} \mathrm{O}, 0.3 \mathrm{~g} / \mathrm{L} \mathrm{MnSO}_{4} \cdot \mathrm{H}_{2} \mathrm{O}, 0.54 \mathrm{~g} / \mathrm{L} \mathrm{CoCl}_{2} \cdot$ $6 \mathrm{H}_{2} \mathrm{O}, 41.76 \mathrm{~g} / \mathrm{L} \mathrm{FeCl}_{3} \cdot 6 \mathrm{H}_{2} \mathrm{O}, 1.98 \mathrm{~g} / \mathrm{L} \mathrm{CaCl}_{2} \cdot 2 \mathrm{H}_{2} \mathrm{O}$, 33.4 $\mathrm{g} / \mathrm{L} \mathrm{Na} \mathrm{N}_{2}$ EDTA (Titriplex III)]. The $\mathrm{pH}$-value was adjusted to 7.5 with $\mathrm{NaOH}$. All medium components were sterilized separately by autoclaving or filtration before mixing.

\section{Inducing media}

For growth under inducing conditions, the previously described modified Wilms-MOPS mineral medium supplemented with $2 \mathrm{~g} / \mathrm{L}$ sterilized lactose as inducing compound [4-6] was used. This medium is referred to as Wilms-MOPS mineral autoinduction medium.

\section{Cultivations and online analysis using RAMOS and BioLector devices}

An overview of the different cultivation steps, applied cultivation systems, as well as the determined online and offline data is given in Figure 1. To allow the comparability of cultivation conditions in RAMOS, separate shake flasks, and BioLector device, the shaking conditions were carefully selected to ensure unlimited growth conditions. By preventing an oxygen limitation, a negative influence on growth can be avoided. In this way, comparable cultivation conditions can be provided in all cultivations systems.

\section{Precultivations}

Precultivations were performed in modified $250 \mathrm{~mL}$ shake flasks in an in-house RAMOS device [32,33] with a filling volume of $10 \mathrm{~mL}$. Commercial versions of the RAMOS device are available from Kuhner AG, Birsfelden, Switzerland or HiTec Zang GmbH, Herzogenrath, Germany. The cultures were grown at $37^{\circ} \mathrm{C}$ using an orbital shaker (ES-X Lab-Shaker, Kuhner AG, Switzerland) with a shaking diameter of $50 \mathrm{~mm}$ and a shaking frequency of $350 \mathrm{rpm}$. For the first precultivation, $10 \mathrm{~mL}$ of TB medium were inoculated with $100 \mu \mathrm{L}$ from a cryoculture. As illustrated in Figure 2 by arrows, cultures were grown for $3 \mathrm{~h}$ and then harvested at an OTR of $40-50 \mathrm{mmol} / \mathrm{L} / \mathrm{h}$. For the second precultivation, $10 \mathrm{~mL}$ of Wilms-MOPS mineral medium were inoculated with culture broth from the first precultivation. The initial optical density $\left(\mathrm{OD}_{600}\right)$ was set at 0.1 . Cultures were grown for $5 \mathrm{~h}$ and were harvested at an OTR of 25$35 \mathrm{mmol} / \mathrm{L} / \mathrm{h}$ (Figures 1 and 2). 


\section{Main cultivations}

The main cultivations were carried out in Wilms-MOPS mineral autoinduction medium in parallel in the RAMOS device, separate shake flasks for generating samples for offline analysis, and the BioLector device (Figure 1). A master mix was inoculated with culture broth from the second precultivation with an initial $\mathrm{OD}_{600}$ of 0.1 , and was distributed among the different cultivation systems.

\section{RAMOS cultivations}

The Respiration Activity MOnitoring System (RAMOS) [33] enables the online measurement of the Oxygen Transfer Rate (OTR) as an indicative parameter for growth and metabolic activity of the investigated organisms. RAMOS cultivations were carried out in modified $250 \mathrm{~mL}$ flasks [32] in the RAMOS device with $10 \mathrm{~mL}$ filling volume. Moreover, cultivations were performed at $37^{\circ} \mathrm{C}$ using an orbital shaker with a shaking diameter of $50 \mathrm{~mm}$ and a shaking frequency of $350 \mathrm{rpm}$.

\section{Shake flask cultivations}

Shake flask cultivations were carried out in conventional $250 \mathrm{~mL}$ Erlenmeyer flasks with $10 \mathrm{~mL}$ filling volume under identical cultivation conditions as described for the RAMOS [32,33] cultivations. The culture broth from separate shake flasks was taken at different time points of the cultivation to measure the carbon source concentrations via HPLC, the product via SDS-PAGE, $\mathrm{pH}$-value and BSLA activity, as well as to determine the plasmid copy number per cell via qPCR.

\section{Microtiter plate cultivations}

Microtiter plate cultivations were conducted in 48well Flowerplates (m2p-labs $\mathrm{GmbH}$, Germany) in the BioLector device $[34,35]$ which allows an online measurement of biomass and product formation per volume. Each well is irradiated with light of a defined wavelength (excitation), so that the backscattered light (indicator for biomass) or fluorescence (indicator for fluorescent products) is detected and analyzed. The filling volume was set at $1 \mathrm{~mL}$. All cultivations were performed at $37^{\circ} \mathrm{C}$ using an orbital shaker with a shaking diameter of $3 \mathrm{~mm}$ and a shaking frequency of $1500 \mathrm{rpm}$.

\section{Offline analysis}

\section{Carbon sources}

The concentrations of the carbon sources glucose, lactose, and glycerol were determined by HPLC (Ultimate, Dionex, Germany), equipped with an organic acid resin column $(250 \times 8 \mathrm{~mm}$, CS Chromatographie Service, Germany). The eluent was $5 \mathrm{mM} \mathrm{H}_{2} \mathrm{SO}_{4}$ at a flow rate of $0.8 \mathrm{~mL} / \mathrm{min}$ and $60^{\circ} \mathrm{C}$. Peaks were detected by recording the refractive index (Shodex RI-101, Shodwa Denko Europe, Germany).

\section{Recombinant protein}

The recombinant protein (BSLA) was analyzed by sodium dodecylsulfate polyacrylamide gel electrophoresis (SDS-PAGE). Either total protein based on biomass was determined or soluble and insoluble fractions based on volume were measured.

For total protein, first the $\mathrm{OD}_{600}$ of the culture was measured. After centrifugation and removal of the supernatant, the $\mathrm{OD}_{600}$ was set at 5 by adding a 3:1mixture of water and four-fold concentrated NuPAGE LDS Sample Buffer (Invitrogen, Germany). The suspension was shaken in a thermo shaker at $1000 \mathrm{rpm}$ and $70^{\circ} \mathrm{C}$ for $10 \mathrm{~min}$. For analysis, the SDS-PAGE device (Invitrogen, Germany) was equipped simultaneously with up to two gels (4-12\% Bis-Tris, Invitrogen, Germany). A volume of $20 \mu \mathrm{L}$ of the prepared samples and $15 \mu \mathrm{L}$ of the protein marker (Roti-Mark Standard, Roth, Germany) were transferred to the gel. The running process was operated according to the manufacturer's instructions (running time $35 \mathrm{~min}$, maximum current $200 \mathrm{~V}$, and maximum power $0.25 \mathrm{~W})$. The gels were stained overnight in Roti-Blue staining solution (Roth, Germany) under gentle shaking at room temperature and destained with $25 \%$ methanol for $2 \mathrm{~h}$. Target protein content relative to the total cellular protein was determined after electrophoresis by densitometry within the TotalLab TL100 (TotalLab Ltd, UK) software using one-dimensional gel analysis: lanes were created automatically; background was subtracted using the rolling ball method with a radius of 100; and detection of protein bands was done with a minimal slope of 100 .

For determining the soluble and insoluble protein fractions, a cell pellet from $200 \mu \mathrm{L}$ culture broth was suspended in $300 \mu \mathrm{L}$ of BugBuster Protein Extraction Reagent (Novagen, Merck, Germany) with added DNase I (25 U/mL; Applichem, Germany) and lysozyme (1000 $\mathrm{U} / \mathrm{mL}$; Roth, Germany). The suspension was incubated at room temperature under gentle shaking for $20 \mathrm{~min}$ and subsequently centrifuged at $14000 \mathrm{rpm}$ at $4^{\circ} \mathrm{C}$ for $20 \mathrm{~min}$. Afterwards, the supernatant containing the soluble protein was transferred to a new reaction tube, while the pellet containing the insoluble protein was suspended in $300 \mu \mathrm{L}$ water. Sample volumes of $60 \mu \mathrm{L}$ of either the supernatant or the suspended pellet, were mixed with $20 \mu \mathrm{L}$ of four-fold concentrated sample buffer and shaken in a thermo shaker at $1000 \mathrm{rpm}$ and $70^{\circ} \mathrm{C}$ for $10 \mathrm{~min}$. The gel loading (4-12\% Bis-Tris, Invitrogen, Germany), the running process, as well as the gel staining were performed as described for the 
Table 4 Sequences of primers for qPCR

\begin{tabular}{lllll}
\hline Target & Primers $\left(\mathbf{5}^{\prime} \rightarrow \mathbf{3}^{\prime}\right)^{\mathbf{a}}$ & Length $(\mathbf{n t})$ & Primer position & Product size $(\mathbf{b p})$ \\
\hline Bla & F: AGTTCTGTCTCGGCGCGTCT & 20 & $1331-1350$ & 96 \\
T7 RNApol & R: ACTCCAGTCGCCTCCCGTT & 20 & $1426-1445$ & 116 \\
& F: AGGACTGCTTACGCTGGCGA & 20 & $1488-1507$ & $1603-1622$ \\
\hline
\end{tabular}

${ }^{\mathrm{a}} \mathrm{F}$ and $\mathrm{R}$ indicate forward and reverse primers, respectively.

determination of the total protein. After electrophoresis, the ratio of insoluble to soluble protein fraction was determined using densitometry within the TotalLab TL 100 (TotalLab Ltd, UK) software. The peak areas of the respective protein bands from insoluble and soluble protein fraction referring to a standard band from protein marker (43 kDa; Roti-Mark Standard, Roth, Germany) were analyzed and the ratio of insoluble to soluble protein fraction was calculated (Table 3).

\section{pH-value}

The $\mathrm{pH}$-value was measured using an InLab Easy $\mathrm{pH}$ electrode (Mettler Toledo, Germany) with a CyberScan pH 510 meter (Eutech Instruments, Thermo Scientific, Germany).

\section{BSLA activity}

BSLA activity was determined in cell pellets obtained from $5 \mathrm{~mL}$ culture broth suspended in $1 \mathrm{~mL}$ BugBuster Protein Extraction Reagent (Novagen, Merck Germany) with added DNase I (25 U/mL; Applichem, Germany) and lysozyme (1000 U/mL; Roth, Germany). The mixture was incubated at room temperature under gentle shaking for $20 \mathrm{~min}$ and centrifuged at $14000 \mathrm{rpm}$ at $4^{\circ} \mathrm{C}$ for $20 \mathrm{~min}$. BSLA activity was measured with colorless para-nitrophenol butyrate ( $p \mathrm{NPB})$ as the substrate. A volume of $90 \mu \mathrm{L}$ of $50 \mathrm{mM}$ potassium phosphate buffer ( $\mathrm{pH} 8)$ and $10 \mu \mathrm{L}$ of the supernatant from protein extraction were filled into a well of a 96-well microtiter plate and $100 \mu \mathrm{L}$ of substrate solution composed of $2.63 \mu \mathrm{L} p \mathrm{NPB}, 1.5 \mathrm{~mL}$ acetonitrile, and $13.5 \mathrm{~mL} 50 \mathrm{mM}$ potassium phosphate buffer ( $\mathrm{pH} 8$ ), was added. The reaction kinetics were monitored for $5 \mathrm{~min}$ through the increase in absorption at $410 \mathrm{~nm}$ caused by the release of yellow paranitrophenolate from the substrate.

\section{Plasmid copy number}

The copy number of plasmids per genome copies was determined by real-time quantitative polymerase chain reaction (qPCR) [69]. Two primer sets specific to the $\beta$-lactamase gene (bla) and to the T7 RNA polymerase gene (T7 RNApol) were designed using the Primer3 web server [70]. The primer sequences are shown in Table 4 (synthetized by eurofins MWG Operon,
Germany). Total DNA extraction from culture broth was performed using the QIAamp DNA Mini kit (Qiagen, Germany), following a method for bacterial cells described in the manual. The concentration of extracted DNA was quantified using a NanoDrop 2000c instrument (Thermo Scientific, Germany) and diluted to $2 \mathrm{ng} / \mu \mathrm{L}$. The qPCR mixture was prepared using Power SYBR Green PCR Master Mix (Applied Biosystems, Life Technologies, Thermo Fisher Scientific, Germany). The thermal cycling protocol was performed according to manufacturer's instructions on a Mastercycler ep realplex (Eppendorf, Germany). The thermal cycling steps were as follows: initial denaturation at $95^{\circ} \mathrm{C}$ for $10 \mathrm{~min}$ followed by 40 cycles of $15 \mathrm{~s}$ at $95^{\circ} \mathrm{C}$ and $1 \mathrm{~min}$ at $60^{\circ} \mathrm{C}$. After the amplification, a melting curve analysis with a temperature gradient from $60-95^{\circ} \mathrm{C}$ was performed to confirm that only specific products were amplified. The relative quantification referring to genome copies was performed by the $\Delta \Delta \mathrm{C}_{\mathrm{T}}$ method [71].

\section{Additional files}

Additional file 1: Investigated target proteins. (A) $\mathrm{His}_{6}$ tag (polyhistidin tag) fused to LOV tag (FbFP, flavin-based fluorescent protein based on the Light, Oxygen, Voltage (LOV) domain of the Bacillus subtilis YtvA photoreceptor), molecular weight $15 \mathrm{kDa}$. (B) His ${ }_{6}$ tag fused to LOV tag and wild-type lipase (BSLA, B. subtilis lipase A) or BSLA variants containing single amino acid exchanges, molecular weight $35 \mathrm{kDa}$.

Additional file 2: Cultivations of $E$. coli BL21(DE3) without plasmid under non-inducing and inducing conditions. Oxygen transfer rate (OTR) as a function of time obtained from four independent replicate experiments for: (A) first preculture performed in complex TB medium, (B) second preculture performed in Wilms-MOPS mineral medium, and (C) main culture performed in Wilms-MOPS mineral autoinduction medium. Cultivation conditions: $37^{\circ} \mathrm{C}, 250 \mathrm{~mL}$ flasks, filling volume $10 \mathrm{~mL}$, shaking frequency $350 \mathrm{rpm}$, and shaking diameter $50 \mathrm{~mm}$.

Additional file 3: Cultivations of 15 E. coli BL21(DE3) clones in complex autoinduction medium expressing fusion tags, wild type BSLA, or different BSLA variants as specified in Table 1. Oxygen transfer rate (OTR) as a function of time for 15 E. coli BL21(DE3) clones (1-8: top, 9-15: bottom) in complex autoinduction medium (commercial Overnight Express Instant TB medium, Novagen, Merck, Germany). Cultivation conditions: $37^{\circ} \mathrm{C}, 250 \mathrm{~mL}$ flasks, filling volume $10 \mathrm{~mL}$, shaking frequency $350 \mathrm{rpm}$, and shaking diameter $50 \mathrm{~mm}$.

Additional file 4: Reproducibility of biomass formation of $15 \mathrm{E}$. coli BL21(DE3) clones under inducing conditions expressing fusion tags, wild type BSLA, or different BSLA variants as specified in Table 1. Biomass (scattered light) as function of time obtained from 2-6 independent replicate experiments performed in Wilms-MOPS mineral autoinduction 
medium containing $0.5 \mathrm{~g} / \mathrm{L}$ glucose, $2 \mathrm{~g} / \mathrm{L}$ lactose and $5 \mathrm{~g} / \mathrm{L}$ glycerol. The measured data is presented as dots, the arithmetic mean as line, and the standard deviation as colored area around the arithmetic mean. Type A clones are presented with white background, Type B clones with grey background. Cultivation conditions: $37^{\circ} \mathrm{C}$, 48-well Flowerplate, filling volume $1 \mathrm{~mL}$, shaking frequency $1500 \mathrm{rpm}$, shaking diameter $3 \mathrm{~mm}$.

Additional file 5: Reproducibility of product formation of $15 \mathrm{E}$. col BL21(DE3) clones under inducing conditions expressing fusion tags, wild type BSLA, or different BSLA variants as specified in Table 1.

Product (fluorescence) as function of time obtained from 2-6 independent replicate experiments performed in Wilms-MOPS mineral autoinduction medium containing $0.5 \mathrm{~g} / \mathrm{L}$ glucose, $2 \mathrm{~g} / \mathrm{L}$ lactose and $5 \mathrm{~g} / \mathrm{L}$ glycerol. A reference from 3 independent replicate experiments performed in non-inducing Wilms-MOPS mineral medium containing $0.5 \mathrm{~g} / \mathrm{L}$ glucose and $5 \mathrm{~g} / \mathrm{L}$ glycerol is presented for the clone expressing the wild type enzyme. The measured data is presented as dots, the arithmetic mean as line, and the standard deviation as colored area around the arithmetic mean. Type A clones are presented with white background, Type B clones with grey background. Cultivation conditions: $37^{\circ} \mathrm{C}$, 48 -well Flowerplate, filling volume $1 \mathrm{~mL}$, shaking frequency $1500 \mathrm{rpm}$, shaking diameter $3 \mathrm{~mm}$.

Additional file 6: Detailed characterization of two E. coli BL21(DE3) clones belonging to respiration behavior Type $B$ cultivated under inducing conditions. Characteristic growth parameters (oxygen transfer rate, biomass formation, product formation, and carbon source concentrations) of two E. coli BL21(DE3) clones belonging to respiration behavior Type B (BSLA variants $112 \mathrm{C}$ and F17P) during the cultivation in Wilms-MOPS mineral autoinduction medium. The five cultivation phases (I-V) are specified in Figure 7. Cultivation conditions: $37^{\circ} \mathrm{C}$, $250 \mathrm{~mL}$ flasks, filling volume $10 \mathrm{~mL}$, shaking frequency $350 \mathrm{rpm}$, shaking diameter $50 \mathrm{~mm}$ (in RAMOS); $37^{\circ} \mathrm{C}$, 48-well Flowerplate, filling volume $1 \mathrm{~mL}$, shaking frequency $1500 \mathrm{rpm}$, shaking diameter $3 \mathrm{~mm}$ (in BioLector).

\section{Abbreviations}

a.u.: Arbitrary unit; BSLA: Bacillus subtilis lipase A; E. coli: Escherichia coli; FbFP: Flavin-based fluorescent protein; HPLC: High performance liquid chromatography; IPTG: Isopropyl $\beta$-D-1-thiogalactopyranoside; LOV: Light, oxygen, voltage; OTR: Oxygen transfer rate; (q)PCR: (quantitative) polymerase chain reaction; RAMOS: Respiration activity monitoring system; SDSPAGE: Sodium dodecylsulfate polyacrylamide gel electrophoresis.

\section{Competing interests}

The authors declare that they have no competing interests.

\section{Authors' contributions}

NR designed this study, participated in cultivation experiments and drafted the manuscript. AF carried out the site-directed mutagenesis and participated in data interpretation. $\mathrm{NI}$ and $\mathrm{MM}$ performed the cultivation experiments. KEJ participated in data interpretation and assisted in drafting the manuscript. JB supervised the study and assisted in drafting the manuscript. All authors read and approved the final manuscript.

\section{Acknowledgements}

We acknowledge financial support from German Research Foundation (DFG) within the research training group 1166 "Biocatalysis using Non-Conventional Media - BioNoCo". We thank all members for helpful discussions in this project.

\section{Author details}

'AVT - Biochemical Engineering, RWTH Aachen University, Worringerweg 1, D-52074 Aachen, Germany. ${ }^{2}$ Institute for Molecular Enzyme Technology, Heinrich-Heine-University Düsseldorf, Forschungszentrum Jülich, D-52426, Jülich, Germany. ${ }^{3}$ Institute of Bio- and Geosciences IBG-1: Biotechnology, Forschungszentrum Jülich GmbH, D-52426 Jülich, Germany.

Received: 23 June 2014 Accepted: 5 January 2015

Published online: 23 January 2015

\section{References}

1. Hannig G, Makrides SC. Strategies for optimizing heterologous protein expression in Escherichia coli. Trends Biotechnol. 1998;16:54-60.
2. Terpe K. Overview of bacterial expression systems for heterologous protein production: from molecular and biochemical fundamentals to commercial systems. Appl Microbiol Biotechnol. 2006;72:211-22.

3. Studier FW, Moffatt BA. Use of bacteriophage-T7 RNA-polymerase to direct selective high-level expression of cloned genes. J Mol Biol. 1986;189:113-30.

4. Studier FW. Protein production by auto-induction in high-density shaking cultures. Protein Expr Purif. 2005;41:207-34.

5. Blommel PG, Becker KJ, Duvnjak P, Fox BG. Enhanced bacterial protein expression during auto-induction obtained by alteration of lac repressor dosage and medium composition. Biotechnol Prog. 2007;23:585-98.

6. Li Z, Kessler W, van den Heuvel J, Rinas U. Simple defined autoinduction medium for high-level recombinant protein production using T7-based Escherichia coli expression systems. Appl Microbiol Biotechnol. 2011;91:1203-13.

7. Inada T, Kimata K, Aiba HJ. Mechanism responsible for glucose-lactose diauxie in Escherichia coli: Challenge to the CAMP model. Genes Cells. 1996;:293-301.

8. Glick BR. Metabolic load and heterologous gene-expression. Biotechnol Adv. 1995:13:247-61.

9. Bentley WE, Mirjalili N, Andersen DC, Davis RH, Kompala DS. Plasmidencoded protein - the principal factor in the metabolic burden associated with recombinant bacteria. Biotechnol Bioeng. 1990;35:668-81.

10. Bhattacharya SK, Dubey AK. Metabolic burden as reflected by maintenance coefficient of recombinant Escherichia coli overexpressing target gene. Biotechnol Lett. 1995;17:1155-60.

11. Neubauer P, Lin HY, Mathiszik B. Metabolic load of recombinant protein production: Inhibition of cellular capacities for glucose uptake and respiration after induction of a heterologous gene in Escherichia coli. Biotechnol Bioeng. 2003:83:53-64.

12. Makrides SC. Strategies for achieving high-level expression of genes in Escherichia coli. Microbiol Rev. 1996;60:512-38.

13. Baneyx F. Recombinant protein expression in Escherichia coli. Curr Opin Biotechnol. 1999;10:411-21.

14. Sorensen HP, Mortensen KK. Advanced genetic strategies for recombinant protein expression in Escherichia coli. J Biotechnol. 2005;115:113-28.

15. Flores $\mathrm{S}$, de Anda-Herrera R, Gosset G, Bolivar FG. Growth-rate recovery of Escherichia coli cultures carrying a multicopy plasmid, by engineering of the pentose-phosphate pathway. Biotechnol Bioeng. 2004;87:485-94.

16. Striedner G, Pfaffenzeller I, Markus L, Nemecek S, Grabherr R, Bayer K. Plasmid-free T7-based Escherichia coli expression systems. Biotechnol Bioeng. 2010;105:786-94

17. Carneiro S, Ferreira EC, Rocha I. Metabolic responses to recombinant bioprocesses in Escherichia coli. J Biotechnol. 2013;164:396-408.

18. Lee J, Ramirez WF. Mathematical-modeling of induced foreign proteinproduction by recombinant bacteria. Biotechnol Bioeng. 1992;39:635-46.

19. Kunze M, Huber R, Gutjahr C, Mullner S, Büchs J. Predictive tool for recombinant protein production in Escherichia coli shake-flask cultures using an on-line monitoring system. Biotechnol Prog. 2012;28:103-13.

20. Palmen TG, Nieveler J, Frölich B, Treffenfeldt W, Pohl M, Büchs J. Physiological relation between respiration activity and heterologous expression of selected benzoylformate decarboxylase variants in Escherichia coli. Microb Cell Fact. 2010;9:76.

21. Bonomo J, Gill RT. Amino acid content of recombinant proteins influences the metabolic burden response. Biotechnol Bioeng. 2005;90:116-26.

22. Akashi $\mathrm{H}$, Gojobori T. Metabolic efficiency and amino acid composition in the proteomes of Escherichia coli and Bacillus subtilis. Proc Natl Acad Sci U S A. 2002;99:3695-700.

23. Kaleta C, Schäuble S, Rinas U, Schuster S. Metabolic costs of amino acid and protein production in Escherichia coli. Biotechnol J. 2013;8:1105-67.

24. Harcum SW, Bentley WE. Response dynamics of $26-k D a, 34-k D a, 39-k D a$, $54-\mathrm{kDa}$, and $80-\mathrm{kDa}$ proteases in induced cultures of recombinant Escherichia coli. Biotechnol Bioeng. 1993;42:675-85.

25. Harcum SW. Structured model to predict intracellular amino acid shortages during recombinant protein overexpression in E. coli. J Biotechnol. 2002;93:189-202.

26. Grossman AD, Taylor WE, Burton ZF, Burgess RR, Gross CA. Stringent response in Escherichia coli induces expression of heat shock proteins. J Mol Biol. 1985;186:357-65.

27. Heyland J, Blank LM, Schmid A. Quantification of metabolic limitations during recombinant protein production in Escherichia coli. J Biotechnol. 2011;155:178-84. 
28. Nemecek S, Marisch K, Juric R, Bayer K. Design of transcriptional fusions of stress sensitive promoters and GFP to monitor the overburden of Escherichia coli hosts during recombinant protein production. Bioprocess Biosyst Eng. 2008;31:47-53.

29. Hoffmann F, Rinas U. On-line estimation of the metabolic burden resulting from the synthesis of plasmid-encoded and heat-shock proteins by monitoring respiratory energy generation. Biotechnol Bioeng. 2001;76:333-40.

30. Seoane J, Sin G, Lardon L, Gernaey KV, Smets BF. A new extant respirometric assay to estimate intrinsic growth parameters applied to study plasmid metabolic burden. Biotechnol Bioeng. 2010;105:141-9.

31. Silva F, Queiroz JA, Domingues FC. Evaluating metabolic stress and plasmid stability in plasmid DNA production by Escherichia coli. Biotechnol Adv. 2012;30:691-708

32. Anderlei T, Büchs J. Device for sterile online measurement of the oxygen transfer rate in shaking flasks. Biochem Eng J. 2001;7:157-62.

33. Anderlei T, Zang W, Papaspyrou M, Büchs J. Online respiration activity measurement (OTR, CTR, RQ) in shake flasks. Biochem Eng J. 2004;17:187-94.

34. Samorski M, Muller-Newen G, Büchs J. Quasi-continuous combined scattered light and fluorescence measurements: A novel measurement technique for shaken microtiter plates. Biotechnol Bioeng. 2005;92:61-8.

35. Kensy F, Zang E, Faulhammer C, Tan R-K, Büchs J. Validation of a high-throughput fermentation system based on online monitoring of biomass and fluorescence in continuously shaken microtiter plates. Microb Cell Fact. 2009;8:31.

36. van Pouderoyen G, Eggert T, Jaeger K-E, Dijkstra BW. The crystal structure of Bacillus subtilis lipase: A minimal alpha/beta hydrolase fold enzyme. J Mol Biol. 2001;309:215-26.

37. Drepper T, Eggert T, Circolone F, Heck A, Krauss U, Guterl J-K, et al. Reporter proteins for in vivo fluorescence without oxygen. Nat Biotechnol. 2007:25:443-5

38. Krauss U, Lee J, Benkovic SJ, Jaeger K-E. LOVely enzymes - towards engineering light-controllable biocatalysts. Microb Biotechnol. 2010;3:15-23.

39. Losen M, Frölich B, Pohl M, Büchs J. Effect of oxygen limitation and medium composition on Escherichia coli fermentation in shake-flask cultures. Biotechnol Prog. 2004;20:1062-8.

40. Luli GW, Strohl WR. Comparison of growth, acetate production, and acetate inhibition of Escherichia coli strains in batch and fed-batch fermentations. Appl Environ Microbiol. 1990;56:1004-11.

41. Ponce $E$. Effect of growth rate reduction and genetic modifications on acetate accumulation and biomass yields in Escherichia coli. J Biosci Bioeng. 1999:87:775-80.

42. Held D, Yaeger K, Novy R. New coexpression vectors for expanded compatibilities in E. coli. inNovations. 2003;18:4-6.

43. Mason CA, Bailey JE. Effects of plasmid presence on growth and enzyme-activity of Escherichia coli DH5-alpha. Appl Microbiol Biotechnol. 1989;32:54-60.

44. Valenzuela MS, Ikpeazu EV, Siddiqui KAI. E. coli growth inhibition by a high copy number derivative of plasmid pBR322. Biochem Biophys Res Commun. 1996:219:876-83.

45. Seo JH, Bailey JE. Effects of recombinant plasmid content on growth properties and a cloned gene product formation in Escherichia coli. Biotechnol Bioeng. 1985;27:1668-74.

46. Birnbaum S, Bailey JE. Plasmid presence changes the relative levels of many host-cell proteins and ribosome components in recombinant Escherichia coli. Biotechnol Bioeng. 1991;37:736-45.

47. Cheah UE, Weigand WA, Stark BC. Effects of recombinant plasmid size on cellular processes in Escherichia coli. Plasmid. 1987;18:127-34.

48. Smith MA, Bidochka MJ. Bacterial fitness and plasmid loss: the importance of culture conditions and plasmid size. Can J Microbiol. 1998:44:351-5.

49. Grossman TH, Kawasaki ES, Punreddy SR, Osburne MS. Spontaneous CAMP-dependent derepression of gene expression in stationary phase plays a role in recombinant expression instability. Gene. 1998;209:95-103.

50. Fu X-Y, Wei D-Z, Tong W-Y. Effect of yeast extract on the expression of thioredoxin-human parathyroid hormone from recombinant Escherichia coli. J Chem Technol Biotechnol. 2006;81:1866-71.

51. Nystrom T. Stationary-phase physiology. Annu Rev Microbiol. 2004:58:161-81.

52. Siepert E-M, Gartz E, Tur MK, Delbrueck H, Barth S, Büchs J. Short-chain fluorescent tryptophan tags for on-line detection of functional recombinant proteins. BMC Biotechnol. 2012;12:65.

53. Kottmeier K, Weber J, Müller C, Bley T, Büchs J. Asymmetric division of Hansenula polymorpha reflected by a drop of light scatter intensity measured in batch microtiter plate cultivations at phosphate limitation. Biotechnol Bioeng. 2009;104:554-61.

54. Dasilva NA, Bailey JE. Theoretical growth-yield estimates for recombinant cells. Biotechnol Bioeng. 1986;28:741-6.

55. Jensen EB, Carlsen S. Production of recombinant human growth-hormone in Escherichia coli - expression of different precursors and physiological-effects of glucose, acetate, and salts. Biotechnol Bioeng. 1990;36:1-11.

56. Linchao S, Bremer $\mathrm{H}$. Effect of the bacterial-growth rate on replication control of plasmid pBR322 in Escherichia coli. Mol Gen Genet. 1986;203:143-9.

57. Summers DK. The kinetics of plasmid loss. Trends Biotechnol. 1991;9:273-8.

58. Summers D. Timing, self-control and a sense of direction are the secrets of multicopy plasmid stability. Mol Microbiol. 1998;29:1137-45.

59. Goff SA, Goldberg AL. Production of abnormal proteins in Escherichia coli stimulates transcription of ion and other heat-shock genes. Cell. 1985;41:587-95.

60. Hoffmann F, Rinas U. Stress induced by recombinant protein production in Escherichia coli. Adv Biochem Eng Biotechnol. 2004;89:73-92.

61. Rinas U, Bailey JE. Protein compositional analysis of inclusion-bodies produced in recombinant Escherichia coli. Appl Microbiol Biotechnol. 1992:37:609-14.

62. Rinas U, Boone TC, Bailey JE. Characterization of inclusion-bodies in recombinant Escherichia coli producing high-levels of porcine somatotropin. J Biotechnol. 1993;28:313-20.

63. Fahnert B, Lilie $H$, Neubauer P. Inclusion bodies: formation and utilisation. Adv Biochem Eng Biotechnol. 2004;89:93-142.

64. Zhu S, Gong C, Ren L, Li X, Song D, Zheng G. A simple and effective strategy for solving the problem of inclusion bodies in recombinant protein technology: His-tag deletions enhance soluble expression. Appl Microbiol Biotechnol. 2013:97:837-45.

65. Edelheit O, Hanukoglu A, Hanukoglu I. Simple and efficient site-directed mutagenesis using two single-primer reactions in parallel to generate mutants for protein structure-function studies. BMC Biotechnol. 2009;9:61.

66. Bertani G. Studies on lysogenesis. I. The mode of phage liberation by lysogenic Escherichia coli. J Bacteriol. 1951;62:293-300.

67. Tartof KD, Hobbs CA. Improved media for growing plasmid and cosmid clones. Bethesda Res Lab Focus. 1987:9:12.

68. Wilms B, Hauck A, Reuss M, Syldatk C, Mattes R, Siemann M, et al. High-celldensity fermentation for production of L-N-carbamoylase using an expression system based on the Escherichia coli rhaBAD promoter. Biotechnol Bioeng. 2001;73:95-103.

69. Lee C, Kim J, Shin SG, Hwang S. Absolute and relative QPCR quantification of plasmid copy number in Escherichia coli. J Biotechnol. 2006;123:273-80.

70. Rozen S, Skaletsky H. Primer3 on the WWW for general users and for biologist programmers. Methods Mol Biol. 2000;132:365-86.

71. Livak KJ, Schmittgen TD. Analysis of relative gene expression data using real-time quantitative PCR and the 2(T)(-Delta Delta C) method. Methods. 2001:25:402-8.

\section{Submit your next manuscript to BioMed Central and take full advantage of:}

- Convenient online submission

- Thorough peer review

- No space constraints or color figure charges

- Immediate publication on acceptance

- Inclusion in PubMed, CAS, Scopus and Google Scholar

- Research which is freely available for redistribution 